2003s-51

\title{
Modeling the Dynamics of Credit Spreads with Stochastic Volatility
}

\author{
Kris Jacobs, Xiaofei Li
}

Série Scientifique
Scientific Series

Montréal

Août 2003

(C) 2003 Kris Jacobs, Xiaofei Li. Tous droits réservés. All rights reserved. Reproduction partielle permise avec citation du document source, incluant la notice $\odot$.

Short sections may be quoted without explicit permission, if full credit, including $\odot$ notice, is given to the source.
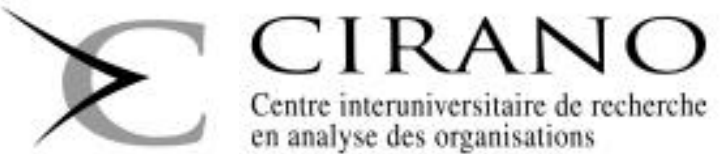

Centre interuniversitaire de recherche

en analyse des organisations 


\section{CIRANO}

Le CIRANO est un organisme sans but lucratif constitué en vertu de la Loi des compagnies du Québec. Le financement de son infrastructure et de ses activités de recherche provient des cotisations de ses organisationsmembres, d'une subvention d'infrastructure du ministère de la Recherche, de la Science et de la Technologie, de même que des subventions et mandats obtenus par ses équipes de recherche.

CIRANO is a private non-profit organization incorporated under the Québec Companies Act. Its infrastructure and research activities are funded through fees paid by member organizations, an infrastructure grant from the Ministère de la Recherche, de la Science et de la Technologie, and grants and research mandates obtained by its research teams.

Les organisations-partenaires / The Partner Organizations

PARTENAire Majeur

. Ministère du développement économique et régional [MDER]

PARTENAIRES

. Alcan inc.

. Axa Canada

. Banque du Canada

. Banque Laurentienne du Canada

. Banque Nationale du Canada

. Banque Royale du Canada

. Bell Canada

. Bombardier

. Bourse de Montréal

. Développement des ressources humaines Canada [DRHC]

. Fédération des caisses Desjardins du Québec

- Gaz Métropolitain

. Hydro-Québec

. Industrie Canada

. Ministère des Finances [MF]

. Pratt \& Whitney Canada Inc.

. Raymond Chabot Grant Thornton

. Ville de Montréal

. École Polytechnique de Montréal

. HEC Montréal

. Université Concordia

. Université de Montréal

. Université du Québec à Montréal

. Université Laval

. Université McGill

AsSOCIÉ À :

. Institut de Finance Mathématique de Montréal (IFM ${ }^{2}$ )

. Laboratoires universitaires Bell Canada

. Réseau de calcul et de modélisation mathématique $\left[\mathrm{RCM}^{2}\right]$

. Réseau de centres d'excellence MITACS (Les mathématiques des technologies de l'information et des systèmes complexes)

Les cahiers de la série scientifique (CS) visent à rendre accessibles des résultats de recherche effectuée au CIRANO afin de susciter échanges et commentaires. Ces cahiers sont écrits dans le style des publications scientifiques. Les idées et les opinions émises sont sous l'unique responsabilité des auteurs et ne représentent pas nécessairement les positions du CIRANO ou de ses partenaires.

This paper presents research carried out at CIRANO and aims at encouraging discussion and comment. The observations and viewpoints expressed are the sole responsibility of the authors. They do not necessarily represent positions of CIRANO or its partners.

ISSN 1198-8177 


\title{
Modeling the Dynamics of Credit Spreads with Stochastic Volatility"
}

\author{
Kris Jacobs ${ }^{\dagger}$, Xiaofei $\mathrm{Li}^{\ddagger}$
}

\begin{abstract}
Résumé / Abstract
Dans cet article, nous modélisons l'écart de crédit sur obligations d'entreprise avec un modèle affin à deux facteurs. Le premier facteur s'interprète comme le niveau de l'écart et le deuxième comme sa volatilité. Le taux d'intérêt sans risque est modélisé selon un modèle affin à deux facteurs standard, ce qui conduit à un modèle à quatre facteurs pour les rendements d'obligations d'entreprise. Cette approche nous permet de modéliser la volatilité des écarts de crédit de manière stochastique et également de capter des moments des écarts de crédit d'ordres plus élevés. Nous utilisons une approche de filtre de Kalman étendu pour estimer notre modèle à partir des prix des obligations de 108 entreprises. Le modèle s'avère performant dans sa reproduction des écarts de crédit empiriques des obligations d'entreprise et mène à une racine des erreurs moyennes quadratiques significativement plus petite que celle d'un modèle alternatif standard, et ce aussi bien dans l'échantillon que lors d'analyses hors échantillon. De plus, le modèle capte également mieux certaines caractéristiques empiriques importantes des écarts de crédit sur obligations d'entreprise.
\end{abstract}

Mots clés : risque de crédit; écarts de crédit; modèles à forme réduite; volatilité stochastique.

The paper investigates a two-factor affine model for the credit spreads on corporate bonds. The first factor can be interpreted as the level of the spread, and the second factor is the volatility of the spread. The riskless interest rate is modeled using a standard two-factor affine model, thus leading to a fourfactor model for corporate yields. This approach allows us to model the volatility of corporate credit spreads as stochastic, and also allows us to capture higher moments of credit spreads. We use an extended Kalman filter approach to estimate our model on corporate bond prices for 108 firms. The model is found to be successful at fitting actual corporate bond credit spreads, resulting in a significantly lower root mean square error than a standard alternative model in both in-sample and out-of-sample analyses. In addition, key properties of actual credit spreads are better captured by the model.

Keywords: credit risk, credit spreads, reduced form models, stochastic volatility.

Codes JEL : G12

\footnotetext{
${ }^{*}$ Kris Jacobs would like to thank FCAR, SSHRC, IFM2 and CIRANO for financial support. We would like to thank Peter Christoffersen, Jan Ericsson and Jean-Guy Simonato for very helpful conversations and comments. ${ }^{\dagger}$ Associate Professor of Finance, McGill University and CIRANO. Faculty of Management, McGill University, 1001 Sherbrooke Street West, Montreal, Canada, H3A 1G5, tel. (514) 398-4025, fax: (514) 398-3876, email: Kris.Jacobs@mcgill.ca.

${ }^{\ddagger}$ Ph.D. Candidate, McGill University.
} 


\section{Introduction}

Understanding the pricing of default risk or credit risk is of critical importance since almost every financial security is affected by certain types of credit risk. Over the last decade, the financial industry has come under increasing pressure to understand and quantify this risk, because of the growth in financial markets that trade credit sensitive products, and because of increasing scrutiny from regulators. As a result, the academic literature on modeling credit risk has been growing fast. Currently, there are two main approaches to modeling credit risk. The first approach is called the structural approach, first developed in Merton (1974). The models used in the structural approach are based on the value of the firm. In these models default is regarded as an endogenous decision usually made by the firm's equityholders. The second approach is called the reduced form approach. It considers default as both a surprise and an exogenous event. This approach uses stochastic processes similar to those used in the modeling of the riskless term structure to model the default probability (see e.g. Madan and Unal (1994) and Duffie and Singleton (1999)). The models used in this approach have proven to be relatively easier to use for practical applications. This paper presents a reduced form model of credit risk. In particular, we use a two-factor affine model to describe the joint dynamics of the instantaneous default probability and the volatility of the default probability.

There are compelling reasons for incorporating stochastic volatility into models of default probability and credit spreads. According to the contingent claim analysis in Merton (1974), the corporate bond price is equal to the price difference between a riskless bond and a put option written on the assets of the firm. Since volatility plays a crucial role in pricing options, it will also have a major impact on corporate bond prices and yields. It is therefore critically important to model volatility correctly. At the empirical level, academics and practitioners have long noted that the volatility of credit spreads changes through time. To illustrate this feature of credit spread data, consider Figures 1 and 2, which plot different time series of credit spread indices for different ratings from Moody's and Standard \& Poor's, respectively (these data are described in more detail below). Figure 3 also plots the relative changes for the credit spreads from Moody's. These figures clearly show that the volatility of credit spreads is time-varying. Relative changes in credit spreads were significantly larger during the first halves of the sample periods. In his analysis of credit spreads, Duffee (1999, p.198) finds "persistent fluctuations in the volatilities of yields (GARCH-like effects) that are not captured by the model." Miu (2001) reaches similar conclusion and argues for introducing volatility as a second factor in the default probability process. Finally, the market for credit derivatives has been expanding dramatically since 1990s. Since volatility is fundamental to pricing derivative securities, a stochastic volatility model of credit spreads will help us to more accurately value credit derivatives such as credit spread options, and to more properly manage the credit risk of fixed-income portfolios.

A stochastic volatility model can also capture the skewness naturally embedded in credit 
data. Because one component of the risky bond price is a put option, the Merton (1974) model also implies that its distribution is negatively skewed. Therefore we expect to find positive skewness for the distributions of risky yields and spreads. Tables 1 and 2 present summary statistics for the Moody's and Standard \& Poor's credit spread indices. Table 1 provides strong evidence of positive skewness in credit spreads. The evidence in Table 2 is more mixed, with some series displaying (small) negative skewness and others displaying (relatively larger) positive skewness. The credit spread model in this paper can capture this skewness.

The objectives of this paper are two-fold. First, we propose a new reduced form model of credit risk that explicitly accounts for stochastic volatility in default probability and the correlation between the riskless interest rate and default probability, and we estimate the model using prices of U.S. Treasury bonds and corporate bonds. Second, we compare the performance of our model to an alternative model that is developed in Duffee (1999), in which stochastic volatility in default probability is not explicitly taken into account. We estimate our model and the alternative model on data of month-end corporate bond prices from January 1985 to March 1998. In total, the data consist of more than 44,000 bondprice observations across 108 firms. These bonds are primarily investment-grade. For every firm, we divide the available data into two sub-periods: the last 12 months are used for out-of-sample forecasting, and the rest are used for in-sample estimation.

Overall, the stochastic volatility model fits corporate yields much better than the alternative model. At the aggregate level, the median in-sample RMSE of our model is 9.30 basis points (bps), versus 11.99 bps for the alternative model; in the out-of-sample analysis, the stochastic volatility model achieves an median RMSE of 12.05 bps, relative to $13.89 \mathrm{bps}$ for the alternative model. More importantly, at the individual firm level, the stochastic volatility model realizes a lower in-sample RMSE than the competing model for every single firm in the sample and a lower out-of-sample RMSE for slightly more than two-thirds of firms in the sample. The parameter estimates indicate that the probability of default is mean-reverting under the physical measure and can also be mean-reverting under the risk-neutral measure in the stochastic volatility model, whereas the estimates of the benchmark model indicate that the probability of default is mean-reverting under the physical measure but mean-averting under the risk-neutral measure. For the vast majority of the firms, the default probability and credit spreads are found to be strongly negatively correlated with the default-free interest rate. This finding is consistent with many previous empirical studies. To investigate the robustness of our findings, we also repeat the estimation using credit spread indices. These estimation results confirm our findings obtained using individual firm data.

This paper is part of a growing list of articles that empirically test reduced form models of credit risk. ${ }^{1}$ Madan and Unal (1994) examine yields on certificates of deposit issued by thrift

\footnotetext{
${ }^{1}$ Recent empirical studies that estimate structural models of credit risk include Eom, Helwege, and Huang (2000) and Ericsson and Reneby (2001). In addition, using numerical simulations, Huang and Huang (2000)
} 
institutions. Grinblatt (1995), Duffie and Singleton (1997), Liu, Longstaff, and Mandell (2000), and Collin-Dufresne and Solnik (2001) study interest rate swap yields. Nielsen and Ronn (1997) use data on both corporate bonds and interest rate swap yields. Duffee (1999), Bakshi, Madan, and Zhang (2001), and Miu (2001) analyze corporate bond prices of individual firms. All of these applications, including ours, are special cases of the affine family of term structure models. However, our model specification is new in the context of credit spreads, and it is easy to implement.

The rest of the paper is organized as follows. Section 2 introduces the two models used in the empirical analysis. Section 3 discusses the data. The estimation method is discussed in Section 4. Section 5 reports the basic results. Section 6 further explores the empirical results. Finally, Section 7 concludes the article. All technical details can be found in the Appendix B.

\section{Models of corporate bond prices}

This section consists of three parts. Section 2.1 describes the proposed stochastic volatility model of credit spreads. Section 2.2 briefly summarizes Duffee's (1999) model, which is used as a benchmark. In this model, stochastic volatility of credit spreads is not explicitly accounted for. In Section 2.3, we discuss the stochastic volatility model in more detail, including the parameterization of the model, assumptions on the recovery rate, and the pricing of coupon bonds.

\subsection{A model of credit spreads with stochastic volatility}

First consider the default-free interest rate. Under the physical (or actual) probability measure $P$, the instantaneous nominal riskless interest rate is denoted by $i_{t}$, and is assumed to be equal to the sum of a constant, $c$, and two factors that follow independent square-root diffusion processes

$$
\begin{gathered}
i_{t}=c+f_{1 t}+f_{2 t}, \\
d f_{i t}=\phi_{i}\left(\mu_{i}-f_{i t}\right) d t+\sigma_{i} \sqrt{f_{i t}} d w_{i t},
\end{gathered}
$$

for $i=1$, 2. In equation (2), $\phi_{i}$ denotes the speed of mean reversion of factor $f_{i t}$, and $\mu_{i}$ can be interpreted as the long-run mean of $f_{i t}, i=1,2$. The two standard Brownian motions $w_{1 t}$ and $w_{2 t}$ are assumed to be independent. The specification in equations (1) and (2) has appeared in Cox, Ingersoll, and Ross (1985) and Pearson and Sun (1994), and the latter calls it a translated square-root model, due to the presence of the constant term $c$. This model

compare the performances of several well-known structural models of corporate debt. 
belongs to the class of exponential affine (or simply affine) term structure of interest rate models. ${ }^{2}$

Following Cox, Ingersoll, and Ross (1985), we write the process in (2) under the riskneutral probability measure $Q$ as

$$
d f_{i t}=\left(\phi_{i} \mu_{i}-\left(\phi_{i}+\pi_{i}\right) f_{i t}\right) d t+\sigma_{i} \sqrt{f_{i t}} d \widehat{w}_{i t},
$$

where $\pi_{i}(i=1,2)$ are the risk premiums and $\widehat{w}_{1 t}$ and $\widehat{w}_{2 t}$ are two independent Brownian motions under the measure $Q$. Notice that in this model, $\pi_{i}<0(i=1,2)$ implies that investors demand positive compensation for bearing interest rate risk.

The choice of the above riskless interest rate model was driven by three considerations. First, it is well known that the dynamics of riskless yield curves can not be adequately captured by a single factor. Instead, at least a two-factor model should be used. According to Litterman and Scheinkman (1991), the first two factors account for nearly $96 \%$ of variations in yield curves. Second, the above specification permits a well-known and simple closedform solution for zero-coupon bond prices (see e.g. Pearson and Sun (1994)), which greatly facilitates estimation. Third, this interest rate model results in a reasonably good fit for the risk free term structure.

As is common in all reduced form models, default is assumed to occur when an exogenous Poisson process with intensity $\lambda$ jumps (see Lando (1997)). Under the equivalent martingale measure $Q$, the intensity of this Poisson process for firm $j$ at time $t$ is denoted by $\lambda_{j t}$, which can be interpreted as follows. Consider a firm $j$ that is not in default at time $t$. Under the measure $Q$, the probability that this firm defaults during a subsequent sufficiently small time interval $(t, t+d t)$, conditioning on the information available at time $t$, is $\lambda_{j t} d t$. Consequently, we may interpret $\lambda_{j t}$ as the instantaneous default probability. Different reduced form models are mainly characterized by different specifications for $\lambda_{j t}$.

Next, consider a zero-coupon bond issued by firm $j$, which promises to pay one dollar at the maturity date of $T$, unless the firm defaults before $T$. If default occurs, the bondholders recover nothing. We denote by $B_{j}(t, T, 0,0)$ the price of this bond at time $t$, where the third argument in $B_{j}(t, T, 0,0)$ refers to the coupon rate, and the fourth argument denotes the recovery rate. We will relax the zero-recovery assumption and examine coupon bonds in Section 2.3. Under certain regularity conditions (see Duffie and Singleton (1999)), this corporate bond price is given as

$$
B_{j}(t, T, 0,0)=E_{t}^{Q}\left\{\exp \left[-\int_{t}^{T}\left(i_{u}+\lambda_{j u}\right) d u\right]\right\},
$$

where $i_{t}+\lambda_{j t}$ is the so-called "adjusted discount rate" for firm $j$ at time $t$, and $E_{t}^{Q}(\cdot)$ denotes

\footnotetext{
${ }^{2}$ Duffie and Kan (1996) characterize affine term structure of interest rate models. Dai and Singleton (2000) conduct a thorough specification analysis of various affine interest rate models.
} 
the conditional expectation under the risk-neutral probability measure $Q$, relying on all the information available at time $t$.

It is clear from equation (4) that for a near-maturity, zero-coupon, and zero-recovery corporate bond, the instantaneous default probability, $\lambda_{j t}$, can also be interpreted as the instantaneous credit spread on this bond. Consequently, we will use the terms "instantaneous default probability" and "credit spreads" interchangeably in this article; they both refer to $\lambda_{j t}$. It should be pointed out that $\lambda_{j t}$, the default probability, may be interpreted in a broader sense, since the spread between risky and riskless yields also results from factors other than default risk, such as the liquidity premium or state tax differences.

In this paper, we model default probability as a two-factor affine process under the physical measure $P$

$$
\begin{aligned}
& \lambda_{j t}= c_{j}+\lambda_{j t}^{*}+\delta_{1 j}\left(f_{1 t}-\overline{f_{1 t}}\right)+\delta_{2 j}\left(f_{2 t}-\overline{f_{2 t}}\right), \\
& d \lambda_{j t}^{*}=\alpha\left(\bar{\lambda}-\lambda_{j t}^{*}\right) d t+\sqrt{v_{j t}} d z_{1 j, t}, \\
& d v_{j t}=\gamma\left(\bar{v}-v_{j t}\right) d t+\xi \sqrt{v_{j t}} d z_{2 j, t},
\end{aligned}
$$

where $v_{j t}$ is the instantaneous variance of the default probability of firm $j$ at time $t ; \bar{\lambda}$ and $\bar{v}$ are the unconditional (or long-run) means of $\lambda_{j t}^{*}$ and $v_{j t}$, respectively; $\alpha$ and $\gamma$ capture the mean-reversion of $\lambda_{j t}^{*}$ and $v_{j t}$, respectively; and $\xi$ is the "volatility of volatility" parameter, which determines the kurtosis of $\lambda_{j t}^{*}$.

The two standard Brownian motions $z_{1 j, t}$ and $z_{2 j, t}$ are correlated with coefficient $\rho$, which is positively correlated with the skewness of credit spreads. This feature of the model enables us to capture the skewness exhibited by the distribution of credit spreads. Furthermore, we assume that $z_{1 j, t}$ and $z_{2 j, t}$ are independent of the two Brownian motions $w_{1 t}$ and $w_{2 t}$ in the default-free interest rate process. Finally, $\overline{f_{1 t}}$ and $\overline{f_{2 t}}$ are the means of the smoothed estimates of the two riskless interest rate factors, $f_{1 t}$ and $f_{2 t}$, over the sample period of corporate bonds.

Again using a standard assumption of prices of risk, the stochastic processes followed by $\lambda_{j t}^{*}$ and $v_{j t}$ under the risk-neutral measure $Q$ are given by

$$
\begin{aligned}
d \lambda_{j t}^{*} & =\left(\alpha \bar{\lambda}-\alpha \lambda_{j t}^{*}+\eta_{1} v_{j t}\right) d t+\sqrt{v_{j t}} d \widehat{z}_{1 j, t} \\
d v_{j t} & =\left(\gamma \bar{v}-\left(\gamma+\xi \eta_{2}\right) v_{j t}\right) d t+\xi \sqrt{v_{j t}} d \widehat{z}_{2 j, t}
\end{aligned}
$$

where again the two standard Brownian motions $\widehat{z}_{1 j, t}$ and $\widehat{z}_{2 j, t}$ have a correlation coefficient of $\rho$ and they are independent of the Brownian motions $\hat{w}_{1 t}$ and $\hat{w}_{2 t}$ in the default-free interest rate process. Also, $\eta_{i}(i=1,2)$ are the risk premium parameters. Note that in this model, $\eta_{1}>0$ and $\eta_{2}<0$ indicate a positive risk premium in $\lambda_{j t}^{*}$ and $v_{j t}$, respectively.

The model for $\lambda_{j t}^{*}$ and $v_{j t}$ in equation (5) is inspired by Fong and Vasicek (1991), who use similar dynamics to model the default-free interest rate. The model is a member of the affine family of interest rate models and has a closed-form solution for zero-coupon bond 
prices. Since the solution is quite complicated and involves complex algebra, we use a series solution method suggested in Selby and Strickland (1995) to compute bond prices in this paper. The Selby and Strickland method has proven to be both accurate and fast. Appendix B.1.1 contains a brief introduction to their method.

The specification in (5) and (6) captures, in a tractable way, three prominent empirical features of actual credit spreads. First, credit spreads (and default probability) appear to vary stochastically over time. The stochastic $\lambda_{j t}^{*}$ term within $\lambda_{j t}$ accounts for this feature. Second, the volatility of credit spreads is itself stochastic. This fact is modeled parsimoniously by a stochastic $v_{j t}$. Third, credit spreads on corporate bonds non-trivially depend on the movements of default-free interest rates. In the model, this dependence is solely captured by the $\delta_{1 j}$ and $\delta_{2 j}$ coefficients in $\lambda_{j t}$, due to the assumed independence of the Brownian motions driving the riskless interest rate and the default probability.

\subsection{A benchmark model}

To evaluate the empirical performance of the stochastic volatility credit spread model, we also estimate a benchmark model. The benchmark model that we use is the model developed in Duffee (1999). The default-free interest rate component of his model is identical to the specification in equations (1), (2), and (3).

Under the $P$ measure, Duffee (1999) models the default probability using a one-factor translated square-root process with two components linked to the riskless term structure

$$
\begin{gathered}
\lambda_{j t}=c_{j}+\lambda_{j t}^{*}+\delta_{1 j}\left(f_{1 t}-\overline{f_{1 t}}\right)+\delta_{2 j}\left(f_{2 t}-\overline{f_{2 t}}\right), \\
d \lambda_{j t}^{*}=\kappa_{j}\left(\theta_{j}-\lambda_{j t}^{*}\right) d t+\sigma_{j} \sqrt{\lambda_{j t}^{*}} d u_{j t},
\end{gathered}
$$

where the standard Brownian motion $u_{j t}$ is independent of the two Brownian motions $w_{1 t}$ and $w_{2 t}$ in the riskless interest rate process.

Under the risk-neutral measure, the process for $\lambda_{j t}^{*}$ is given by

$$
d \lambda_{j t}^{*}=\left(\kappa_{j} \theta_{j}-\left(\kappa_{j}+\pi_{j}\right) \lambda_{j t}^{*}\right) d t+\sigma_{j} \sqrt{\lambda_{j t}^{*}} d \widehat{u}_{j t},
$$

in which $\pi_{j}(<0)$ is the risk premium, and the Brownian motion $\widehat{u}_{j t}$ is independent of the Brownian motions $\widehat{w}_{1 t}$ and $\widehat{w}_{2 t}$ in the riskless interest rate specification.

Notice that in the Duffee model, the volatility of the credit spreads, $\sigma_{j} \sqrt{\lambda_{j t}^{*}}$, is not constant but time-varying due to the stochastic nature of $\lambda_{j t}^{*}$. However, instead of modeling the credit spread volatility as a separate diffusion process, in his model the volatility of the credit spreads is proportional to the level of the spreads itself and can not move independently of $\lambda_{j t}^{*}$.

Together, equations (1) through (3) and (7) through (8) constitute a three-factor affine model of corporate bond yields, and equations (7) and (8) alone result in a one-factor affine 
model of credit spreads. Henceforth we will refer to this model as the Duffee model or the benchmark model. This model leads to well-known closed-form solutions for corporate zerocoupon bond price. In contrast, the four-factor affine model of corporate yields in equations (1) through (3) and (5) through (6) has an additional factor that captures the stylized fact that the volatility of credit spreads is stochastic. Henceforth we will refer to this model as the stochastic volatility model of credit spreads, or for short the stochastic volatility model, even though the volatility of the riskless component of the risky yield is not formally modeled. ${ }^{3}$ Notice that the four-factor model does not nest the three-factor benchmark model since in the special case where the $v_{j t}$ process in equation (5) reduces to a constant, the process for $\lambda_{j t}^{*}$ in equation (5) becomes a so-called Ornstein-Uhlenbeck process, similar to the one used in Vasicek (1977), which is different from the square-root process for $\lambda_{j t}^{*}$ in equation (7). ${ }^{4}$

\subsection{Further discussion of the stochastic volatility model}

Denote the "adjusted discount rate" for firm $j$ at time $t$ by $R_{j t} \equiv i_{t}+\lambda_{j t} L_{j t}$, where $L_{j t}$ is the expected loss rate of firm $j$ 's defaultable bond's value if default were to occur at time $t$, and the product term $\lambda_{j t} L_{j t}$ is called the mean loss rate (Duffie and Singleton (1999)). It follows that the recovery rate of firm $j$ at time $t$ is equal to $1-L_{j t}$. For simplicity, in our discussion in Section 2.1, we have assumed no recovery upon default, i.e., $L_{j t}=1$. We now relax this no-recovery assumption. When the recovery rate is non-zero, i.e., when $0 \leq L_{j t}<1$, the price of a zero-coupon corporate bond with a recovery rate of $1-L_{j t}$, $B_{j}\left(t, T, 0,1-L_{j t}\right)$, is given by

$$
\begin{aligned}
B_{j}\left(t, T, 0,1-L_{j t}\right) & =E_{t}^{Q}\left\{\exp \left[-\int_{t}^{T}\left(i_{u}+\lambda_{j u} L_{j u}\right) d u\right]\right\} \\
& =E_{t}^{Q}\left\{\exp \left[-\int_{t}^{T} R_{j u} d u\right]\right\}
\end{aligned}
$$

When using the above pricing relationship, we may either parameterize $R_{j t}$ directly, or parameterize the components of $R_{j t}$, namely, $i_{t}, \lambda_{j t}$, and $L_{j t}$, individually. Duffie and Singleton (1997) and Dai and Singleton (2000) take the former approach to modeling the

\footnotetext{
${ }^{3}$ It is worth pointing out that our model and the Duffee model share a common weakness: in both settings, the default probability, $\lambda_{j t}$, can become negative, which is conceptually odd. In our model, $\lambda_{j t}$ may become negative because the stochastic process followed by $\lambda_{j t}^{*}$ allows $\lambda_{j t}^{*}$ to take negative values. On the other hand, in the Duffee model, $\lambda_{j t}$ may fall below zero if either $c_{j}$ or $\delta_{i j}(i=1,2)$ is negative.

${ }^{4}$ We also estimated the nested three-factor affine model of corporate yields in which the process for $\lambda_{j t}^{*}$ is given by an Ornstein-Uhlenbeck process. The performance of this nested model is worse than that of the benchmark model.
} 
term structure of interest-rate swap yields. The latter approach is adopted by Duffee (1999) and Collin-Dufresne and Solnik (2001), where they parameterize $i_{t}$ and the product term $\lambda_{j t} L_{j t}$ separately. In this paper, we choose to parameterize $i_{t}$ and $\lambda_{j t} L_{j t}$ separately in order to extract information about the mean loss rate $\lambda_{j t} L_{j t}$ from historical defaultable bond prices. This information can be used to value other defaultable claims, such as credit default swaps.

In this paper, we assume that if default were to occur at $\tau_{d}, t<\tau_{d} \leq T$, the bondholders would receive, upon default, a fixed fraction of $(1-L)$ of the face value of the original corporate bond. In other words, in the event of default, the corporate bondholders are assumed to receive a fixed $(1-L)$ unit of an otherwise identical default-free bond for every one dollar of the face value of the original default-risky bond. Jarrow, Lando, and Turnbull (1997) and Duffee (1999) make a similar assumption on the recovery rate.

The assumption of a constant recovery rate $(1-L)$ can be justified by two findings. First, a recent empirical study in Skinner and Diaz (2001) discovers that for the purpose of accurately pricing defaultable bonds, a stochastic recovery rate is of only second-order importance, relative to e.g. a correct parameterization of default probability. Second, as pointed out in Duffie and Singleton (1999), since $\lambda_{j t}$ and $L_{j t}$ only appear in the pricing relationship (9) as a cross product term, it is impossible to identify them separately by using data on corporate bonds alone. Instead, data on credit derivatives, of which payoffs are nonlinearly dependent on $\lambda_{j t}$ and $L_{j t}$, are required. Since the main focus of this paper is on modeling default probability $\lambda_{j t}$, a constant recovery rate assumption makes identification of $\lambda_{j t}$ possible. It also permits a closed-form solution of bond prices, which significantly facilitates estimation. However, it should be kept in mind that the framework can be extended to accommodate a stochastic recovery rate without additional conceptual difficulty.

We set the recovery rate at $44 \%$ of par in our empirical work. This is consistent with Moody's finding that the average recovery rate of senior unsecured bonds is approximately $44 \%$ of the par value (of the original bond) if default occurs. A similar assumption is made in Duffee (1999), who fixes the recovery rate at $44 \%$ of par, and also in Duffie and Lando (2001), who assume a constant recovery rate of $43.3 \%$.

Applying a standard no-arbitrage argument, we can write the before-default price of a zero-coupon corporate bond with a constant recovery rate of $(1-L)$ as

$$
B_{j}(t, T, 0,1-L)=(1-L) G(t, T, 0)+L B_{j}(t, T, 0,0),
$$

where $G(t, T, 0)$ denotes the price at time $t$ of a default-free zero-coupon bond that matures at time $T$.

The bulk of the corporate bond data consist of coupon bonds. We use the so-called "portfolio of zeros" approach to valuing corporate coupon bonds. In Appendix B.1.2, we define this approach and provide theoretical justifications for its use in the present context. Appendix B.1.2 also contains the formulas for coupon bonds. 


\section{Data}

\subsection{Data on the risk free interest rate}

Month-end US Treasury prices (the averages of the reported bid and ask prices) from January 1985 to March 1998 are obtained from the CRSP US Treasury Cross-Sectional File. In each month, the most recently issued (or on-the-run) noncallable Treasury bills, notes or bonds with maturities closest to 3 and 6 months and 1, 2, 3, 5, 10 and 30 years are selected. ${ }^{5}$

\subsection{Data on corporate bonds}

Month-end corporate bond bid prices are collected from the Fixed Income Securities Database (also known as the Lehman Brothers Fixed Income Database or the Warga Database) over the period beginning January 1985 and ending March 1998, encompassing a sample period of 159 months. Before 1985, firms rarely issued non-callable bonds. Hence we only use a sample period starting in January 1985. All price observations included in the sample are indicative trader-quoted prices. That is, prices that were calculated using a matrix algorithm are dropped. Only investment-grade, non-callable, non-putable, senior unsecured straight bonds with semi-annual coupons and no sinking fund provisions, having remaining maturities no longer than 35 years and no shorter than 1 year, are selected. Only those firms for which there are at least three bonds (not necessarily the same bonds) outstanding in a given month for at least 48 months (not necessarily consecutively) are considered. Finally, we only include bonds in the sample that make up the Lehman Brothers bond index or are about to enter the index. There are 108 firms that satisfy all of the above requirements. Among these firms, 65 are industrial firms, 28 are financial firms, and 15 are utility firms. The final data set consists of a total of 44,298 qualified bond price observations. Appendix A contains a complete listing of the corporations included in the dataset.

In some instances, we compare estimation results across credit ratings. To do so, we use the bond rating supplied by Moody's, which defines a firm's credit rating as the rating on its senior unsecured bonds. The credit rating assigned to a firm in the sample is the mean of the ratings of the firm's bonds used in estimation. This procedure results in 12 Aa-rated firms, 60 A-rated firms, and 36 Baa-rated firms. That is, the sample is dominated by A- and Baa-rated firms. ${ }^{6}$

\footnotetext{
${ }^{5}$ Duffee (1999) uses data on the second most recently issued (or off-the-run) U.S. Treasury securities in order to avoid capturing any special liquidity premium associated with the on-the-run Treasury securities. He reports no material difference between on-the-runs and off-the-runs. As a robustness check, we also estimate our riskless interest rate model using off-the-run data and the results are very similar to those obtained using on-the-runs. We therefore only report results on on-the-runs. Several other empirical studies, e.g. Duffie and Singleton (1997) and Miu (2001), also use the on-the-run U.S. Treasury data.

${ }^{6}$ In our original sample, there were also 3 Aaa-rated firms. We have excluded them from our subsequent analyses for two reasons. First, the limited sample size makes any inference from the results on these firms
} 
Table 3 contains summary statistics for the corporate bond data. Panel A reports that the median firm has 73 months of valid bond price observations, while none of the firms in the sample has valid observations in every month. The second row of Panel A in Table 3 reports the mean number of fitted bonds per month, which is calculated over those months in which a firm has at least three qualified bonds outstanding. The median number of fitted bonds is 4.4 , and the maximum number is 12.36 . Therefore, although across all the firms and the entire sample period this article uses 44,298 bond price observations, the credit spreads for the median firm are estimated using just 4 bonds per month. For some firms, certain parameters are therefore estimated imprecisely. The third, fourth, and fifth rows of Panel A report the remaining years to maturity of the bonds used in estimation. The median firm has a minimum maturity of 1.06 years, a mean maturity of 7.92 years, and a maximum maturity of 20.25 years. Finally, according to the last row of Panel A, the median firm has a mean annual coupon rate of $8.37 \%$. For one firm (Allied Corp.), the data set exclusively contains zero-coupon bonds.

Panels B and C present means (in bps), standard deviations (in \%), skewness and kurtosis for yields and credit spreads in this sample. The credit spreads in Panel $\mathrm{C}$ are calculated as the differences between the yields (used in Panel B) and the riskless interest rates implied by the default-free term structure model. The median firm has a mean yield of $709.56 \mathrm{bps}$ and a mean credit spread of 246.07 bps. Similar to the findings in Table 1 and Table 2, yields and credit spreads in this sample exhibit significant positive skewness. There is not much evidence of excess kurtosis in either the yield data or the credit spread data.

To demonstrate the robustness of our results, we repeat the empirical exercise using credit spread indices. The advantage of this type of data is that they span a much longer time horizon than the individual firm data. We obtain Moody's 10-year and 30-year Aaa and Baa monthly credit spread indices from the Federal Reserve Board's G.13 release. The sample periods are January 1960 to April 2003 for 10-year maturity spreads and February 1977 to February 2002 for 30-year maturity spreads. We also obtain weekly credit spread index data for various maturities from Standard \& Poor's for the sample period August 6, 1996 to September 11, 2001. The time series plots of a subset of these data are in Figure 1 and Figure 2, respectively, and Figure 3 presents the relative changes in the spreads for the Standard and Poor's data. Tables 1 and 2 present descriptive statistics for these data. As mentioned before, the Moody's data display positive skewness, while the Standard \& Poor's data in some cases display small negative skewness, and large positive skewness in other cases.

inconclusive. Second, in our sample, the average actual yield on these 3 Aaa-rated firms is higher than those on the Aa-, A-, and Baa-rated firms, and the mean actual credit spread for these 3 firms is higher than that for the Aa-rated firms. This is an anomaly likely caused by the very limited sample size of the Aaa-rated firms. 


\section{Estimation methodology}

These two models can be estimated using a number of different methods. We adopt the extended Kalman filter (EKF) approach to estimate the riskless interest rate and corporate bond models. This approach has been successfully used in, among others, Claessens and Pennacchi (1996), Babbs and Nowman (1999), de Jong (2000), Duan and Simonato (1999), Duffee (1999), Geyer and Pichler (1999), and Miu (2001). There are at least three major advantages associated with the EKF approach. First, it allows us to use both cross-sectional and time-series information contained in the riskless bond prices and corporate bond prices. Second, this approach correctly treats the underlying state variables (or factors) as unobservable, which is consistent with the theoretical models. Third, as a by-product of the EKF, estimates of the state variables are also generated, which is useful for our analysis in Section $6 .^{7}$ Appendix B.2.1 contains a brief summary of the EKF approach.

Because of the assumed independence between the Brownian motions driving the riskless interest rate and those underpinning the default probability, we can follow the two-step estimation procedure proposed in Duffee (1999). In the first step, we estimate the defaultfree term structure using U.S. Treasury prices alone. In the second step, we assume that the parameter estimates of the riskless interest rate obtained from stage one are the true parameters and use them to estimate the parameters of the default probability of each individual firm in the sample. That is, we run an EKF to estimate the riskless interest rate in the first step, and in step two we run an EKF for each individual firm to estimate its credit spread process.

\subsection{Estimation of the default-free interest rate}

At time $t$, we observe a cross-section of U.S. Treasury bond prices $G_{t}=\left(G_{1, t}, \ldots, G_{8, t}\right)^{\prime}$. We collect the two unobservable state variables in the vector $F_{t}$. For notational simplicity, we suppress the dependence of the model on the parameters to be estimated and write down the measurement equation and the transition equation of the Kalman filter as

$$
\begin{gathered}
G_{t}=m\left(F_{t}\right)+\epsilon_{t}, \quad E_{t-1}\left(\epsilon_{t} \epsilon_{t}^{\prime}\right)=\Lambda, \\
F_{t}=a+b F_{t-1}+\varsigma_{t}, \quad E_{t-1}\left(\varsigma_{t} \varsigma_{t}^{\prime}\right)=V\left(F_{t-1}\right) .
\end{gathered}
$$

In the measurement equation (11), the function $m\left(F_{t}\right)$ maps the two state variables in $F_{t}$ to bond prices, and we know this mapping in closed-form; $\epsilon_{t}$ is the white noise measurement

\footnotetext{
${ }^{7}$ For nonlinear and non-Gaussian models, such as the two models considered here, the parameter estimates obtained from the EKF may be inconsistent. However, Monte Carlo evidence in Lund (1997), Duan and Simonato (1999), and de Jong (2000) suggests that this inconsistency is of fairly limited importance for the typical sample size encountered in term structure modeling. Duffee and Stanton (2001) advocate the use of the EKF instead of a more sophisticated method in a similar context.
} 
error at time $t$ and has a constant conditional variance-covariance matrix given by $\Lambda$. In the transition equation (12), $\varsigma_{t}$ is also a white noise error term, of which the conditional variancecovariance matrix is $V\left(F_{t-1}\right)$. This matrix depends on the values of the state variables at time $t-1$. The explicit forms of components $a, b$, and $V\left(F_{t-1}\right)$ are presented in Appendix B.2.2.

We assume that the default-free interest rate process is stationary. Therefore, we can use the unconditional moments of factors $f_{1}$ and $f_{2}, \mu_{1}$ and $\mu_{2}$, respectively, to initiate iterations on the riskless interest rate. We write the measurement equation in terms of bond prices instead of yields for two reasons. First, for coupon bonds there is no linear mapping between the state variables of the model and the bond yields. As a result, we have to numerically solve for the yields. We conjecture that the error occurred in this yield extraction process may be carried over to the subsequent estimation process. We emphasize that this is only a conjecture since we are unaware of any empirical study that addresses this issue. Second, writing the measurement equation in terms of prices allows us to analytically calculate the derivatives of the function $m(\cdot)$ with respect to parameters of the model, which facilitates estimation.

Finally, the nonlinear mapping $m(\cdot)$ between the coupon bond prices and the state variables makes identification of all the risk premium parameters of the model possible. This point is made in Dai and Singleton (2000).

\subsection{Estimation of the default probability}

When estimating the default probability of an individual firm in the second step, we consider the parameter estimates obtained from phase one as the true parameters of the model. We also use the smoothed estimates (i.e., estimates based on information through the entire sample) of the two unobserved riskless factors from phase one. These smoothed estimates are produced by the Kalman filter and we denote them by $\widehat{f_{i t}}(i=1,2)$. We take the means of these estimates over those months in which a firm has valid corporate bond price observations. These means are denoted by $\overline{f_{i t}}(i=1,2)$ and they appear in equations (5) and (7).

Consider a given firm $j$. In month $t$, we observe a cross-section of $U_{j t}$ corporate bond prices issued by this firm. We stack these bond prices into a vector $B_{j t}=\left(B_{j, 1, t}, \ldots, B_{j, U_{j t}, t}\right)^{\prime}$. The last time that firm $j$ 's bond prices were observed was in month $t-\tau$, where due to missing observations, $\tau$ is not necessarily equal to one. The measurement and transition equations are (we again ignore the dependence of the model on the parameters to be estimated)

$$
\begin{gathered}
B_{j t}=m_{j}\left(\Sigma_{j t}, F_{t}\right)+\epsilon_{j t}, \quad E_{t-\tau}\left(\epsilon_{j t} \epsilon_{j t}^{\prime}\right)=\Lambda_{j t} \\
\Sigma_{j t}=a_{j}+b_{j} \Sigma_{j, t-\tau}+\varsigma_{j t}, \quad E_{t-\tau}\left(\varsigma_{j t} \varsigma_{j t}^{\prime}\right)=\Gamma\left(\Sigma_{j, t-\tau}\right) .
\end{gathered}
$$

In the measurement equation $(13)$, vector $F_{t}=\left(\widehat{f_{1 t}}, \widehat{f_{2 t}}\right)^{\prime}$. The function $m_{j}(\cdot)$ maps the 
default-risky state variables stored in $\Sigma_{j t}$ and the smoothed estimates of the riskless factors in $F_{t}$ into corporate bond prices $B_{j t}$. (For the stochastic volatility model, $\Sigma_{j t}=\left(\lambda_{j t}^{*}, v_{j t}\right)^{\prime}$; for the benchmark model, $\Sigma_{j t}=\lambda_{j t}^{*}$.) The terms $\epsilon_{j t}, \varsigma_{j t}$, and $\Gamma\left(\Sigma_{j, t-\tau}\right)$ can be interpreted analogously to their counterparts in equations (11) and (12). The $\Lambda_{j t}$ matrix is a $U_{j t} \times U_{j t}$ diagonal matrix with diagonal entry $S_{j}$, the common measurement error variance of the bond prices of firm $j$. We assume a common error variance since for a given firm, the number of bonds and the maturities of the bonds are time-varying.

The functional forms of $a_{j}, b_{j}$, and $\Gamma\left(\Sigma_{j, t-\tau}\right)$ in the transition equation (14) are given in Appendix B.2.2. In addition, in Appendix B.3 we give, in closed-form, the first two conditional moments of the two state variables of the stochastic volatility model of credit spreads. These moments are used in the empirical work and to the best of our knowledge, they have not been presented anywhere before.

Finally, unlike the assumption of stationarity made for the risk-free interest rate, we do not assume that the default probability of an individual firm is stationary because several recent empirical studies on corporate credit spreads, e.g. Pedrosa and Roll (1998), have found strong evidence of unit root (non-stationarity) in credit spread series. As a result, we can not use the unconditional means of the risky state variables in $\Sigma_{j t}$ as starting points for estimating the default probability. Instead, we filter an estimate of the initial values of $\Sigma_{j t}$ and the variance-covariance matrix associated with this estimate out of firm $j$ 's first month bond data. We refer the interested reader to Duffee (1999, p. 208) for further details.

\section{$5 \quad$ Empirical results}

This section is divided into four parts. Section 5.1 summarizes the estimation results on the default-free interest rate. Section 5.2 discusses the in-sample estimation results for the credit spread models. Section 5.3 reports the out-of-sample results. Section 5.4 presents the estimation results on credit spread indices.

\subsection{Results on the riskless interest rate}

Table 4 reports the estimation results on the default-free interest rate model. The robust standard errors for the parameter estimates are calculated using the formulas in White (1982). The standard errors are generally very small, indicating that the riskless model parameters are estimated quite precisely. The parameter estimates imply that the first factor exhibits strong mean-reversion with a half-life of around 1.25 years. In contrast, the second factor exhibits little mean-reversion, with a half-life of more than 34 years. The estimates of the risk premia are both negative, which is consistent with the theoretical model, although the estimate of the second risk premium, $\pi_{2}$, and the associated standard error indicate that $\pi_{2}$ is of little economic significance and is not statistically different from 
zero.

The first factor of the riskless model may be interpreted as the negative of the slope of the riskless term structure. The correlation between the smoothed estimates of this factor and the slope of the Treasury yield curve (defined as the difference between the 30-year Treasury bond yield and the 3-month Treasury bill yield) is -0.95 , and the correlation between the first differences of these two series is -0.82 . On the other hand, the second riskless factor moves closely with long-term Treasury bond yields since the correlation between the smoothed estimates of this factor and the yields on 30-year Treasury bonds is 0.98 , and the first differences of these two series are strongly correlated with correlation coefficient 0.93 . It is common practice in modeling the riskless term structure to interpret one risk-free factor as the slope of the yield curve, while another factor as the level of the yield curve.

The parameter estimates for the riskless term structure are generally consistent with those of, among others, Duan and Simonato (1999), Duffee (1999), and Geyer and Pichler (1999), although the sample periods in these studies are different. Our results are also similar to those in Pearson and Sun (1994), although both their estimation methodology and sample period differ. The fit of this two-factor model to the Treasury yield curves is overall comparable to the results in Duffee (1999). We achieve a much better fit for the short maturities but a slightly inferior fit for long-maturity bonds. Unlike Duffee (1999), who arbitrarily fixes the constant term $c$ at -1 , we estimate this constant along with other parameters of the model. An estimate of -0.48 for $c$, coupled with the estimates of $\mu_{1}$ and $\mu_{2}$, implies a long-run mean of the riskless short rate of around $9 \%$, which is reasonable. Moreover, Duffee (1999) argues that in order for this riskless interest rate model to fit both a low, flat term structure and a high, steep term structure, while at the same time without incurring unrealistically high volatility, we need a negative estimate of the constant term. Our results support his claim.

\section{$5.2 \quad$ In-sample results on credit spread models}

Table 5 summarizes the in-sample RMSE fit of the stochastic volatility model, and Table 6 presents the corresponding RMSE for the benchmark model. Tables 5 and 6 also report the median and interquartile ranges for the parameter estimates. In Appendix A, we break down, firm by firm, the RMSE results for the two models. Notice that here the RMSE is calculated based on the contemporaneous predictions of the state variables in $\Sigma_{j t}$ (i.e., the estimates of $\Sigma_{j t}$ using information available through time $t$ ). This is in contrast to Table 4, where the RMSE is computed using the smoothed estimates (based on information through the entire sample) of the state variables. Duffee (1999) computes the RMSEs similarly.

Since for any given firm, its term structure of credit spreads is estimated using a relatively small number of bonds, the resulting parameter estimates are sometimes not very precise. Also, there are substantial interquartile variations in the parameter estimates, as reported in Table 5 and Table 6 . Consequently, we will concentrate on the median parameter estimates 
and the median RMSEs in the remainder of this section.

Table 5 indicates that in the stochastic volatility model, both the instantaneous default probability (and credit spread) and its volatility are mean-reverting under the physical measure, because both estimates of $\alpha$ and $\gamma$ are positive (see equation (5)). A related study by Prigent, Renault, and Scaillet (2001) also find strong mean-reversion in Moody's credit spread series. Under the risk-neutral measure, we can rewrite equation (6) in a slightly different form as

$$
\begin{aligned}
d \lambda_{j t}^{*} & =\alpha\left(\bar{\lambda}-\lambda_{j t}^{*}+\frac{\eta_{1} v_{j t}}{\alpha}\right) d t+\sqrt{v_{j t}} d \widehat{z}_{1 j, t} \\
d v_{j t} & =\left(\gamma+\xi \eta_{2}\right)\left(\frac{\gamma \bar{v}}{\gamma+\xi \eta_{2}}-v_{j t}\right) d t+\xi \sqrt{v_{j t}} d \widehat{z}_{2 j, t} .
\end{aligned}
$$

Notice that the variance of credit spreads, $v_{j t}$, now appears in the drift term of $\lambda_{j t}^{*}$. Therefore, $\alpha$ is not the mean-reversion parameter for $\lambda_{j t}^{*}$ under the $Q$ measure. The parameter estimates in Table 5 suggest that the term $\frac{\eta_{1} v_{j t}}{\alpha}$ is often positive. It then follows from equation (15) that when $\lambda_{j t}^{*}$ is below its unconditional mean $\bar{\lambda}$ so that $\left(\bar{\lambda}-\lambda_{j t}^{*}\right.$ ) is positive (and $\lambda_{j t}^{*}$ will increase towards its mean level of $\bar{\lambda}$ ), the variance of credit spreads $v_{j t}$ may increase the mean-reversion of credit spreads by making the drift of $\lambda_{j t}^{*}$ bigger. The opposite effect holds when $\lambda_{j t}^{*}$ is above its unconditional mean $\bar{\lambda}$ so that $\left(\bar{\lambda}-\lambda_{j t}^{*}\right)$ is negative (and $\lambda_{j t}^{*}$ will decrease towards $\bar{\lambda}$ ). We conclude that in the stochastic volatility model, the default risk $\lambda_{j t}^{*}$ can exhibit mean-reversion under the risk-neutral measure for reasonable combinations of parameter values. From Table 6 we see that although the default probability exhibits mean-reversion under the physical measure in the Duffee model, it displays mean-aversion $\left(\kappa_{j}+\pi_{j}<0\right.$, see equation (8)) under the $Q$ measure. This finding is consistent with that in Duffee (1999). Finally, the mean-reversion parameter for $v_{j t}$ is $\gamma+\xi \eta_{2}$. The results in Table 5 then show that the volatility of default probability is mean-averting (i.e. non-stationary) for about $50 \%$ of the firms.

In both models, parameters $\delta_{1 j}$ and $\delta_{2 j}$ capture the correlation between credit spreads and the default-free interest rate. Table 5 and Table 6 indicate that the estimates of $\delta_{1 j}$ and $\delta_{2 j}$ are primarily negative and are larger (in absolute terms) than the estimates in Duffee (1999). To appreciate the economic significance of the estimates of $\delta_{1 j}$ and $\delta_{2 j}$, suppose that the first riskless factor $f_{1 t}$ drops by 100 bps. This increases $\lambda_{j t}$ by 0.00475 in the stochastic volatility model and by 0.00242 in the benchmark model, according to the median estimates of $\delta_{1 j}$ in Table 5 and Table 6 , respectively. Given a recovery rate of $44 \%$, this increase in $\lambda_{j t}$ translates into an increase of $26.6 \mathrm{bps}$ and $13.6 \mathrm{bps}$ in the credit spreads on a nearmaturity zero-coupon corporate bond in the stochastic volatility model and in the Duffee model, respectively. Similarly, the median estimates of $\delta_{2 j}$ reported in Table 5 and Table 6 imply that a 100 bps decline in the second riskless factor $f_{2 t}$ corresponds to an increase of 7.5 bps and 3.7 bps in the credit spreads on a near-maturity zero-coupon corporate bond in the stochastic volatility model and in the Duffee model, respectively. A negative relationship 
between the riskless interest rate and credit spreads is consistent with the structural model in e.g. Longstaff and Schwartz (1995): an increase in the risk-free interest rate increases the drift of the process for firm asset value under the measure $Q$. Other things being equal, this increase in firm value will pull the firm further away from the default threshold, increasing the bond prices of the firm, thus lowering the bond credit spreads. This finding of a negative relationship also confirms the results of many previous empirical studies, such as Duffee (1998) and Collin-Dufresne, Goldstein, and Martin (2001). On the other hand, Neal, Rolph, and Morris (2000) and David (2002) suggest that the relationship between credit spreads and the riskless interest rate is not constant, but depends on factors such as maturity and the state of the business cycle.

In Table 5, the estimates of the first risk premium parameter, $\eta_{1}$, are positive, while the estimates of the second risk premium parameter, $\eta_{2}$, are negative. In Table 6 the estimates of the risk premium parameter, $\pi_{j}$, are negative. These results are consistent with the theoretical models developed in Section 2 and imply that investors demand compensation for bearing not only the time-varying default risk but also the risk associated with the stochastic volatility of credit spreads. Finally, note that in Table 5 the estimates of $\eta_{1}$ and $\eta_{2}$ are large numbers (in absolute value). This is due to the fact that in equation (15) $\eta_{1}$ and $\eta_{2}$ appear in the product terms of $\eta_{1} v_{j t}$ and $\xi \eta_{2}$, respectively, and the estimates of $v_{j t}$ and $\xi$ are relatively small.

Table 5 and Table 6 also report the interquartile ranges of the mean fitted values of the state variables of the two models. These fitted values are based on the contemporaneous predictions of the state variables of the models, consistent with the way in which the insample RMSE is computed. Table 5 shows that in the stochastic volatility model, the median firm has a mean instantaneous default probability $\lambda_{j t}$ of $1.8 \%$ per annum, while the corresponding value for the benchmark model in Table 6 is $1.4 \%$ per annum. Both estimates are fairly close to the estimate in Duffee (1999), which is $1.36 \%$ per annum, but of course the default probability in the data is much lower. Also, it is worth noticing that although a negative estimate of $c_{j}$ in the stochastic volatility model might raise the prospect of a negative default probability $\lambda_{j t}$ (see equation (5)), which is theoretically inconsistent, the mean estimates of $\lambda_{j t}$ are always positive, as reported in Table 5 . Table 5 also shows that the median value of the mean instantaneous variance of credit spreads, $v_{j t}$, is 0.0000581 , which translates into an instantaneous volatility of credit spreads of 0.0076 . For the benchmark model, Table 6 reports that the median firm has a mean instantaneous volatility of credit spreads, $\sigma_{j} \sqrt{\lambda_{j t}^{*}}$, of 0.002 , which is lower than the estimate in the stochastic volatility model.

The stochastic volatility model fits the corporate bond prices better than the benchmark model. Table 5 and Table 6 show that the median in-sample RMSE of the stochastic volatility model is $9.30 \mathrm{bps}$, versus $11.99 \mathrm{bps}$ for the benchmark model. In addition, according to Appendix A, the stochastic volatility model generates a lower in-sample RMSE than the benchmark model for every single firm in the sample. As another indication of the better fit 
achieved by the stochastic volatility model, the median estimate of the measurement error

volatility, $\sqrt{S_{j}}$ (see equation (13)), in the stochastic volatility model is 0.369 dollars, while it is 0.611 dollars for the benchmark model (all corporate bonds in the sample have a face value of 100 dollars). The better in-sample fit of the stochastic volatility model should come as no great surprise because it has one more factor than the benchmark model. However, it must be noted that the stochastic volatility model does not nest the benchmark model (see Section 2.2). Therefore, the better in-sample fit achieved by the stochastic volatility model is encouraging.

\subsection{Out-of-sample results on credit spread models}

To evaluate a model's performance, a model's out-of-sample pricing performance is more important. A more richly parameterized model is expected to perform better in-sample than a more sparsely parameterized alternative model, but this may not be the case out-of-sample. The reason is that models with extra parameters may be penalized in an out-of-sample analysis because of the difficulty in identifying those extra parameters, given the limited sample size of available data.

In this paper, we use as the out-of-sample period the last 12 months in which a firm has valid bond price observations. We conduct the out-of-sample test as follows. We use the in-sample parameter estimates from Table 5 and Table 6, together with the smoothed estimates of the riskless factors in the out-of-sample period and the risk-free model parameters (estimated over the entire sample), to generate a sequence of estimates of the default risky state variables in each of the 12 months in the out-of-sample period. We then use these estimates, as well as the in-sample parameter estimates and information on the riskless term structure, to price corporate bonds in the out-of-sample period. Finally, we compute the corresponding RMSE to gauge the out-of-sample performance of the two models.

The out-of-sample results on the stochastic volatility model are presented in the last row in Table 5. The bottom row of Table 6 reports the results on the benchmark model. Again, Appendix A presents the out-of-sample performance of the models on a firm by firm basis. It is clear from Table 5 and Table 6 that the stochastic volatility model compares favorably with the benchmark model in out-of-sample forecasting: the median RMSE in the stochastic volatility model is 12.05 bps, down from 13.89 bps for the Duffee model. Appendix A also shows that in slightly more than two-thirds of the cases (for 75 firms out of the total 108 firms), the stochastic volatility model leads to a lower out-of-sample RMSE than the benchmark model.

\subsection{Results on credit spread indices}

To ensure that the estimation results are robust, we also estimate the stochastic volatility model and the benchmark model on credit spread index data from Standard and Poor's. The 
estimation results are reported in Table $7 \mathrm{~A}$ and Table 7B for the stochastic volatility model and the benchmark model, respectively. The stochastic volatility model achieves a lower RMSE than the benchmark model for every credit rating group. As to parameter estimates, they are generally consistent with those reported in Table 5 and Table 6 . It is interesting to note that the estimates of the constant term $c_{j}$ are negative for the majority of credit spread indices in the Duffee model, in contrast to the estimates presented in Table 6, where they are universally positive.

\section{Exploration of the Empirical Results}

In this section, we further explore the empirical results. This section is further divided into three subsections. In Section 6.1, we discuss the estimation results for the two credit spread models by credit rating. In Section 6.2, we examine the fit of the two models by credit rating and bond maturity. In Section 6.3, we analyze the role played by the constant term $c_{j}$ in the two models.

\subsection{Estimation results for credit spread models by credit rating}

Table 8 reports the median parameter estimates and the median mean fitted values of the state variables for the stochastic volatility model of credit spreads for firms rated Aa, A, and Baa in the sample. In Table 9 we conduct a similar analysis for the benchmark model. The first thing to notice from Table 8 and Table 9 is that there is substantial variation in the estimates across rating classes. While this could be a genuine feature of the data, it is also possible that this finding is due to the lack of precision in the estimates, which is caused by the relatively small number of bond price observations available to estimate an individual firm's term structure of credit spreads.

Table 8 indicates a modest positive relationship between credit spreads and their volatility since the median estimate of $\rho$ for the A-rated group is 0.009 , while the corresponding estimate for the Baa-rated group is 0.018. For the relatively small sample of Aa bonds, the estimate of $\rho$ is much larger. Table 1 and Table 2 also report a positive relationship between credit spreads and their volatility. There we observe that as credit ratings drop, credit spread levels go up and at the same time the standard deviations of credit spreads generally increase, thus resulting in a positive relationship between credit spreads and their volatility. A positive median estimate of $\rho$ for all the three rating groups also confirms the evidence of positive skewness of credit spreads reported in Table 1 and Table 2, since in the stochastic volatility model $\rho$ captures the skewness of credit spreads. The "volatility of volatility" parameter $\xi$ also appears to increase as credit rating declines: the median estimates of $\xi$ for the $A$ and Baa rated groups are higher than that for the Aa-rated group.

In both Table 8 and Table 9 , the estimates of $\delta_{1 j}$ and $\delta_{2 j}$ generally are more negative 
for lower credit ratings, even if the pattern is clearer in Table 8 . For example, in Table 8 the median estimate of $\delta_{1 j}$ for the Aa-rated group is -0.365 , which declines to -0.459 for the A-rated group, then further decreases to -0.558 for the Baa-rated group. Table 8 also reports that the median estimates of $\delta_{2 j}$ are -0.097 for the Aa-rated firms and -0.141 for the A-rated firms. This relationship can be explained intuitively using the Merton (1974) model: other things being equal, a lower-rated firm is closer to the default boundary. The firm value process of such a firm is more sensitive to changes in the riskless interest rate since an increase in the default-free interest rate translates into an increased drift of the firm value process under the risk-neutral measure, which pulls the firm away from the default boundary, increases the firm's bond prices, and decreases its credit spreads (see also Section $5.2)$.

Table 8 and Table 9 also show that the risk premium parameter estimates for both models generally increase in (absolute) magnitude as firms' credit rating worsens. This pattern is consistent with intuition: it implies that investors require higher compensation for bearing the default risk and the volatility risk of credit spreads as firms' credit rating declines.

Table 8 reports the median mean fitted values of $\lambda_{j t}, \lambda_{j t}^{*}$, and $v_{j t}$, and Table 9 reports the median mean fitted values of $\lambda_{j t}, \lambda_{j t}^{*}$, and $\sigma_{j} \sqrt{\lambda_{j t}^{*}}$ (which measures the volatility of credit spreads in the benchmark model) for the three rating groups. These fitted values are based on the contemporaneous predictions of the state variables in the models, which is consistent with Table 5 and Table 6.

The median estimates of $v_{j t}$ and $\sigma_{j} \sqrt{\lambda_{j t}^{*}}$ reveal that the credit spreads of lower-rated firms are generally more volatile than the credit spreads of higher-rated firms. In Table 8 , the median value of $v_{j t}$, the credit spread variance, is 0.0000294 for the Aa-rated firms, and increases to 0.0000715 for the A-rated firms. Although for the Baa-rated firms the median estimate of $v_{j t}$ is lower than that for the A-rated firms, in the results not reported, the $25 \%$ and $75 \%$ inter-quartile values of $v_{j t}$ for the Baa-rated firms are higher than the corresponding values for the A-rated firms. These results also echo the evidence presented in Table 1 and Table 2, where we observe that the standard deviations of lower-rated credit spreads are in general higher than those of their higher-rated counterparts. The higher volatility associated with the credit spreads on lower-rated bonds implies that managers of bond portfolios consisting of mainly lower-rated bonds should pay more attention to hedging their exposure to the volatility risk.

According to the median estimates of $\lambda_{j t}$ reported in Table 8 and Table 9, the lower-rated firms have a higher default probability. For example, in Table 8 the median estimate of $\lambda_{j t}$, the default probability, is $1.2 \%$ for the Aa-rated firms, which rises to $2.8 \%$ for the Baa-rated firms. These findings support the claim that the commonly used credit ratings are a good first indicator of a firm's creditworthiness. 


\subsection{RMSEs of credit spread models by credit rating and maturity}

The last two rows in Table 8 and Table 9 tabulate the median in- and out-of-sample RMSEs for the stochastic volatility model and the benchmark model, respectively. These two tables reveal that the stochastic volatility model has a better fit than the benchmark model in both in- and out-of-sample analyses, resulting in a lower RMSE in both cases for all three rating groups. Also, it is interesting to note that the fit of both models worsens as credit ratings fall; the in- and out-of-sample RMSEs for both models become bigger as credit ratings get worse.

We now examine the fit of the two models from the perspective of individual bonds. In Panel A of Table 10A, we first divide all the qualified bond price observations in the in-sample periods into different maturity groups. We then report and compare the in-sample RMSEs for the stochastic volatility and benchmark models for these maturity groups. Again, the stochastic volatility model produces a lower in-sample RMSE than the benchmark model for bonds in every maturity group. Similarly, Panel A of Table 10B reports and compares the out-of-sample RMSEs for both models for bonds in various maturity groups. The stochastic volatility model achieves a lower out-of-sample RMSE than the benchmark model for every maturity group except for bonds with maturities ranging from 20 years to 25 years. In Panel $\mathrm{B}$ of Table $10 \mathrm{~A}$, we first divide all the valid bond price observations in the in-sample periods into different credit rating classes. We then calculate and report the in-sample RMSEs for both models for bonds within each credit rating class. In Panel B of Table 10B, we conduct a similar analysis on bonds in the out-of-sample periods. We observe from both these two panels that the stochastic volatility model performs better than the benchmark model in not only the in-sample but also the out-of-sample tests. Again, the fit of both models gets worse as bond ratings decline, since both the in-sample and out-of-sample RMSEs of the two models rise as bonds become less creditworthy.

\subsection{Role of the constant term $c_{j}$}

In Figure 4 and Figure 5, we plot the average credit spreads of the Aa-, A-, and Baarated firms for the stochastic volatility model and the benchmark model, respectively. These figures are generated as follows. For every firm in each rating group, we take its parameter estimates and its mean fitted values of $\lambda_{j t}^{*}$ and $v_{j t}$. The parameter estimates for the riskless term structure model are taken from Table 4 , and for simplicity, we have set the two riskless factors, $f_{1 t}$ and $f_{2 t}$, to their sample means over the in-sample period used for estimation of the firm's credit spread term structure. Using all these information, we calculate the credit spreads corresponding to the firm's parameter estimates. We then average across the credit spreads corresponding to all the firms in each rating group and plot the resulting credit spread curves.

In both Figure 4 and Figure 5, the credit spread curves of the lower-rated firms lie above 
those of the higher-rated firms. In addition, both figures show that the credit spread curves of the lower-rated firms are steeper than those of the higher-rated firms. The pattern of the credit spread term structures exhibited in Figure 4 and Figure 5 is consistent with the stylized facts about the investment-grade credit spreads (see e.g. Litterman and Iben (1991) and Fons (1994)).

The median estimate of the constant term $c_{j}$ in the stochastic volatility model is negative, while it is positive in the benchmark model. Duffee (1999) argues that the combination of $c_{j}>0$ and $\kappa_{j}+\pi_{j}<0$ is required for his model to fit both the level and slope of the credit spread curves in Figure 5. His reasoning can be briefly summarized as follows. Because $\kappa_{j}+\pi_{j}<0$ under measure $Q$, investors price the corporate bonds as if the embedded default risk is explosive. That is, they expect $\lambda_{j t}^{*}$ to rise through time. For a fixed value of $\kappa_{j}+\pi_{j}$, a rising $\lambda_{j t}^{*}$ implies a larger drift term in equation (8) and a upward-sloping credit spread curve. However, the slope of the resulting credit spread term structure for higher-rated firms may be too steep to match the slope of the credit spread curve. Therefore, a positive $c_{j}$ is required in order to depress the overall steepness of the yield spread curves. Without the $c_{j}$ parameter, for highly rated firms, the yield spread curves generated by the Duffee model would be too steep to be consistent with those found in the data.

Similarly, the pair of $c_{j}<0$ and $\alpha>0$ is necessary for the stochastic volatility model to fit both the level and slope of the credit spread curves in Figure 4. A positive estimate of $\alpha$ implies that the default risk is mean-reverting (i.e. stationary) under the physical measure and can be mean-reverting as well under the risk-neutral measure (see Section 5.2). That is, investors do not expect $\lambda_{j t}^{*}$ to rise through time. Instead they expect $\lambda_{j t}^{*}$ to likely return to its long-run mean level after a sufficient length of time. (The mean-reversion of $\lambda_{j t}^{*}$ in the stochastic volatility model is moderate since e.g. the median estimate of $\alpha$ for the Arated firms is 0.063 , which implies a half-life of about 11 years.) As a result, the stochastic volatility model will not imply an overly steep credit spread curve for highly rated firms. Consequently, the role played by the constant term $c_{j}$ in the stochastic volatility model is mainly to dilute the effect of $\lambda_{j t}^{*}$ through the sum of $c_{j}$ and $\lambda_{j t}^{*}$ in equation (5), since the estimates of $\lambda_{j t}^{*}$ are comparatively large for the stochastic volatility model, in order to fit the levels of credit spreads.

\section{Conclusion}

This paper presents a two-factor affine model of default probability and credit spreads. The first factor can be interpreted as the level of credit spreads, and the second factor is the volatility of credit spreads. This default risk model also allows for a close relationship between credit spreads and the riskless interest rate, a characteristic supported by the empirical findings.

Using a large sample of corporate bond price data, we compare the stochastic volatility 
model to a benchmark model in which the volatility of credit spreads is not recognized as a distinct state variable. The stochastic volatility model performs better than the benchmark model, resulting in a lower RMSE (in bps) in both in-sample and out-of-sample tests. The properties of actual credit spreads are better captured by the stochastic volatility model. Therefore, the empirical results demonstrate the importance of including the volatility of credit spreads as a second factor in default risk models.

These results question the ability of a single-factor diffusion process to model adequately both the dynamics of credit spreads and the dynamics of credit spread volatility. We propose a multi-factor reduced form model instead. The model is tractable as well as flexible, and the empirical results show that it fits corporate yield curves reasonably well.

In future work, it will be interesting to use the model to value various types of credit derivatives. The use of credit derivatives has been growing at a tremendous pace, reflecting an increase in both transaction volumes and market participants (J.P. Morgan (1999)). All major types of credit derivatives (such as credit default swaps, total return swaps and credit spread options) are significantly affected by changes in credit spreads and default probabilities (Das (1999)). Since the stochastic volatility model approximates the dynamics of credit spreads and default probabilities more realistically and more satisfactorily, it may lead to more accurate pricing of credit derivatives. 
Appendix A: Empirical results (in basis points) firm by firm Firm number Firm name

ALLIED - SIGNAL INC

ALLIED CORP

In-sample Out-of-

Duffee's Stoch. sample Stoch.

model Volati. Duffee's Volati.

model model model

AMERICAN BRANDS

AMERICAN EXPRESS CREDIT

$\begin{array}{llll}8.308 & 6.608 & 12.194 & 12.562\end{array}$

$\begin{array}{llll}12.180 & 8.876 & 13.053 & 11.412\end{array}$

AMERICAN GENERAL FIN CORP

AMR CORPORATION

$\begin{array}{llll}13.401 & 12.163 & 16.451 & 13.047\end{array}$

$\begin{array}{llll}12.924 & 7.675 & 8.744 & 7.602\end{array}$

AON CORP

ARCHER-DANIELS-MIDLAND

17.617

21.442

$15.544 \quad 8.590$

$20.251 \quad 18.440-21.722$

$\begin{array}{llll}4.709 & 3.419 & 8.767 & 8.122\end{array}$

ARCO CHEMICAL CO

ARISTAR INC

ATLANTIC RICHFIELD

AVCO FINANCIAL SERVICES

BAXTER INTERNATIONAL INC

BEAR STEARNS CO, INC

BELL TEL OF PENN

BENEFICIAL CORP

BOEING CO

BOSTON EDISON

BOWATER

BP AMERICA INC

BURLINGTON RESOURCES INC

11.484

14.575

9.725

10.997

12.237

$\begin{array}{lll}7.508 & 18.517 & 14.254\end{array}$

$\begin{array}{llll}15.834 & 14.169 & 18.007 & 17.407\end{array}$

$\begin{array}{llll}9.787 & 7.761 & 12.190 & 11.161\end{array}$

$\begin{array}{llll}11.678 & 8.668 & 7.919 & 7.158\end{array}$

$\begin{array}{llll}5.591 & 5.009 & 12.831 & 8.884\end{array}$

$\begin{array}{llll}4.374 & 2.214 & 6.315 & 6.600\end{array}$

$\begin{array}{llll}13.408 & 10.804 & 31.981 & 17.600\end{array}$

$\begin{array}{llll}8.286 & 8.012 & 11.949 & 11.957\end{array}$

$\begin{array}{llll}9.506 & 9.252 & 11.617 & 11.063\end{array}$

$\begin{array}{llll}16.152 & 15.469 & 17.457 & 15.474\end{array}$

$\begin{array}{llll}5.483 & 3.100 & 8.796 & 8.617\end{array}$

CATERPILLAR INC

$\begin{array}{llll}13.525 & 12.283 & 15.075 & 15.067\end{array}$

CHRYSLER FINANCIA

22.091

15.707

15.186

CIGNA CORPORATION

CIT GROUP HOLDINGS

CITICORP

COASTAL CORPORATION

8.837

12.332

$14.905 \quad 26.102$

6.699

9.046

12.007

10.610

6.874

COCA - COLA ENTERPRISES INC.

COCA-COLA CO

16.922

5.131

COMMERCIAL CREDIT

CONSOLIDATED ED OF NY

12.582

7.139

10.213

15.078

3.472

8.225

CONSOLIDATED NATURAL GAS

10.325

10.857

4.775

8.015

DAYTON HUDSON CORP

DELTA AIRLINES, INC.

19.319

17.991

10.573

17.371

17.383

13.566

10.610

DOLE FOOD CO

DOW CHEMICAL

DOW CHEMICAL B.V.

EATON CORP

ENRON CORP

FEDERAL EXPRESS CORP

FIRST INTERSTATE BANCORP

FORD CAPITAL B.V.

FORD MOTOR

13.167

3.716

15.694

8.557

12.535

11.983

14.949

13.512

10.603

15.330

GENERAL MOTORS

14.286

GENERAL MOTORS ACPT CORP

12.365

22.804

4.376

GREAT WESTERN FIN CORP

GTE CORP

HELLER FINANCIAL, INC

HERTZ CORP

10.818

9.833

11.891

HOUSEHOLD FINANCE

17.371

INTERNATIONAL LEASE FINANCE $\quad 17.403$

INTERNATIONAL PAPER

INTL BUSINESS MACHINES

17.729

14.617

14.549

7.432

11.147

10.556

7.032

10.584

8.339

13.085

$10.304 \quad 17.723$

$9.081 \quad 7.936$

$\begin{array}{lll}17.164 & 18.000 & 15.724\end{array}$

$\begin{array}{lll}2.701 & 12.371 & 5.169\end{array}$

$\begin{array}{lll}8.257 & 16.667 & 14.151\end{array}$

$\begin{array}{lll}7.584 & 11.518 & 10.079\end{array}$

$\begin{array}{lll}10.619 & 13.939 & 11.088\end{array}$

$\begin{array}{lll}16.294 & 9.717 & 8.245\end{array}$

$\begin{array}{lll}16.158 & 13.989 & 8.797\end{array}$

$\begin{array}{lll}12.896 & 13.036 & 14.940\end{array}$

$\begin{array}{lll}14.131 & 13.089 & 14.310\end{array}$

JAMES RIVER CORP $\quad 6.655$

3.475

5.678

17.910

17.124

LEHMAN BROTHERS HOLDINGS INC 5.784

LIMITED, INC

8.002

4.624

16.706

15.514

13.133

12.493

10.940

17.253

8.236

LOUISIANA LAND \& EXPLORATION 12.912

20.355

45.492

12.841

39.707 


\begin{tabular}{|c|c|c|c|c|c|}
\hline 63 & MARTIN MARIETTA & 9.402 & 9.085 & 16.809 & 22.294 \\
\hline 64 & MASCO CORP & 10.832 & 7.479 & 7.861 & 6.707 \\
\hline 65 & MAY DEPARTMENT STORES & 16.221 & 14.658 & 14.948 & 12.438 \\
\hline 66 & MAYTAG CORPORATION & 7.352 & 4.245 & 11.687 & 11.230 \\
\hline 67 & MERRILL LYNCH \& CO. & 11.160 & 9.508 & 14.765 & 7.428 \\
\hline 68 & MOBIL CORP & 12.053 & 8.841 & 15.289 & 9.321 \\
\hline 69 & MORGAN STANLEY GROUP INC & 13.862 & 10.764 & 17.366 & 7.692 \\
\hline 70 & NEW ENGLAND TEL + TEL & 9.509 & 8.038 & 11.737 & 13.298 \\
\hline 71 & NEW YORK TELEPHONE & 10.705 & 10.559 & 11.531 & 9.620 \\
\hline 72 & NORWEST FINANCIAL INC. & 9.290 & 7.636 & 17.681 & 8.399 \\
\hline 73 & OCCIDENTAL PETROLEUM & 21.950 & 15.061 & 7.195 & 13.976 \\
\hline 74 & PACIFIC BELL & 7.331 & 5.624 & 11.095 & 9.597 \\
\hline 75 & PAINE WEBBER INC & 10.829 & 7.982 & 19.399 & 12.668 \\
\hline 76 & PEPSICO INC & 9.009 & 6.711 & 11.952 & 7.841 \\
\hline 77 & PHILIP MORRIS COS. INC & 8.003 & 7.951 & 15.983 & 9.632 \\
\hline 78 & PROCTER + GAMBLE CO & 9.516 & 9.341 & 8.495 & 5.824 \\
\hline 79 & RALSTON PURINA CO & 16.139 & 15.898 & 17.964 & 18.211 \\
\hline 80 & ROCKWELL INTERNATIONAL & 4.922 & 4.101 & 8.249 & 9.112 \\
\hline 81 & SALOMON INC & 6.814 & 4.605 & 13.530 & 9.948 \\
\hline 82 & SCOTT PAPER & 10.828 & 7.306 & 16.037 & 18.292 \\
\hline 83 & SEAGRAM JOSEPH E + SONS & 9.644 & 8.290 & 11.210 & 10.601 \\
\hline 84 & SEARS ROEBUCK + CO & 16.021 & 9.377 & 9.149 & 7.033 \\
\hline 85 & SECURITY PACIFIC CORP & 12.086 & 10.218 & 33.141 & 31.708 \\
\hline 86 & SHOPKO STORES, INC & 22.672 & 16.318 & 29.509 & 27.990 \\
\hline 87 & SOUTHERN CALIF EDISON & 4.125 & 3.776 & 6.954 & 5.638 \\
\hline 88 & SOUTHWEST AIRLINES CO. & 6.858 & 6.267 & 8.611 & 8.815 \\
\hline 89 & SUNAMERICA INC & 14.155 & 11.902 & 22.523 & 23.709 \\
\hline 90 & TELE-COMMUNICATIONS & 17.791 & 16.832 & 33.558 & 37.417 \\
\hline 91 & TENNECO CREDIT CORP & 11.260 & 7.154 & 17.046 & 15.091 \\
\hline 92 & TENNECO INC & 12.219 & 8.375 & 17.154 & 12.218 \\
\hline 93 & TENNESSEE GAS PIPELINE CO & 9.294 & 6.460 & 20.404 & 19.680 \\
\hline 94 & TEXACO CAPITAL INC. & 14.811 & 13.938 & 13.444 & 12.696 \\
\hline 95 & TEXAS EASTERN TRANSMISSN & 3.957 & 3.204 & 6.921 & 6.781 \\
\hline 96 & TEXAS INSTRUMENTS & 7.520 & 3.417 & 13.072 & 7.307 \\
\hline 97 & TIME WARNER ENT & 17.447 & 16.134 & 13.845 & 12.997 \\
\hline 98 & TRANSAMERICA FINANCIAL & 14.577 & 11.218 & 18.815 & 7.912 \\
\hline 99 & UNION OIL OF CALIFORNIA & 9.195 & 8.748 & 5.380 & 6.831 \\
\hline 100 & UNITED AIR LINES INC & 19.939 & 18.421 & 22.845 & 13.736 \\
\hline 101 & USX CORP & 16.598 & 15.883 & 19.262 & 16.754 \\
\hline 102 & WAL-MART STORES, INC & 8.990 & 8.689 & 10.890 & 12.140 \\
\hline 103 & WEYERHAEUSER CO & 13.723 & 12.381 & 15.281 & 14.705 \\
\hline 104 & WHIRLPOOL CORP & 10.116 & 8.134 & 15.698 & 14.365 \\
\hline 105 & WILLAMETTE IND & 10.071 & 7.007 & 18.001 & 17.152 \\
\hline 106 & WILLIAMS COS & 17.444 & 16.007 & 26.410 & 20.446 \\
\hline 107 & XEROX CORP & 13.275 & 9.442 & 6.777 & 8.546 \\
\hline 108 & XEROX CREDIT CORP & 16.672 & 12.971 & 24.225 & 10.964 \\
\hline $25 \%$ & & 9.266 & 7.268 & 11.273 & 8.538 \\
\hline Median & & 11.995 & 9.297 & 13.892 & 12.048 \\
\hline $75 \%$ & & 15.421 & 13.105 & 17.389 & 15.073 \\
\hline
\end{tabular}




\section{Appendix B: Technical appendices}

\section{B.1 Bond pricing formulas}

B.1.1 Solving the Riccati equation using the method of Selby and Strickland (1995)

The class of exponential-affine (or simply affine) term structure models is a class of models in which the yields to maturity are affine functions of some unobservable state variables $X_{t}$, the dynamics of which are assumed to be

$$
d X_{t}=\Pi\left(X_{t} ; \Omega\right) d t+\Psi\left(X_{t} ; \Omega\right) d Z_{t},
$$

where $Z_{t}$ is a vector of independent Brownian motions and $\Omega$ is a vector of the model parameters. The generic form of bond pricing formula for this class of models is

$$
G(t, T, 0)=\exp \left(A(\Omega, T-t)+B(\Omega, T-t) X_{t}\right),
$$

where $G(t, T, 0)$ denotes the time $t$ price of a riskless zero-coupon bond that matures at time $T$. Let $Y_{t}\left(X_{t} ; \Omega, T-t\right)$ denote the time $t$ continuously compounded yield to maturity on this bond, then the formula of this yield is given by

$$
Y_{t}\left(X_{t} ; \Omega, T-t\right)=-\frac{1}{T-t} A(\Omega, T-t)-\frac{1}{T-t} B(\Omega, T-t) X_{t},
$$

which is affine in the state variables $X_{t}$.

In the present context, the stochastic volatility model for $\lambda_{j t}$ in equation (5) leads to a closed-form solution to the price of a default-risky zero-coupon no-recovery bond issued by firm $j$ with a face value of one dollar as

$$
\begin{aligned}
B_{j}(t, T, 0,0)= & \exp \left[-\tau\left(c+c_{j}-\delta_{1 j} \overline{f_{1 t}}-\delta_{2 j} \overline{f_{2 t}}\right)\right] \exp \left[-\lambda_{j t}^{*} D(\tau)+v_{j t} F(\tau)+K(\tau)(B . t)\right. \\
& \cdot E_{t}^{Q}\left[\exp \left(-\int_{t}^{T} f_{1 u}^{*} d u\right)\right] \cdot E_{t}^{Q}\left[\exp \left(-\int_{t}^{T} f_{2 u}^{*} d u\right)\right]
\end{aligned}
$$

where $f_{i t}^{*} \equiv f_{i t}\left(1+\delta_{i j}\right), i=1,2$, and $\tau \equiv T-t$. The first exponential component of the solution in equation (B.4) is a constant, and the two conditional expectation terms in (B.4) can be solved in simple closed-form (see e.g. Pearson and Sun (1994)).

In equation (B.4), the three functions $D, F$, and $K$ have the time to maturity, $\tau$, as their only variable. They are the solutions to the following system of ordinary differential equations (ODEs)

$$
\begin{gathered}
D^{\prime}+\alpha D-1=0, \quad D(0)=0 ; \\
F^{\prime}=\frac{1}{2} \xi^{2} F^{2}-\left(\gamma+\xi \eta_{2}\right) F-\rho \xi D F-\eta_{1} D+\frac{1}{2} D^{2}, \quad F(0)=0 ; \\
K^{\prime}=-\alpha \bar{\lambda} D+\gamma \bar{v} F, \quad K(0)=0 .
\end{gathered}
$$


In the above system of ODEs, $D^{\prime}$ denotes $\frac{\partial D}{\partial \tau}, F^{\prime}$ and $K^{\prime}$ are defined analogously; and $D(0)=0, F(0)=0$, and $G(0)=0$ are the initial conditions.

The ODE in (B.5), which is for function $D$, can be solved in simple closed-form as $D(\tau)=\frac{1}{\alpha}\left(1-e^{-\alpha \tau}\right)$, and function $K$ can be found by direct integration once we know both $D$ and $F$. The difficult part lies in finding the solution to the ODE for $F$ in (B.6), which is a Riccati equation. A Riccati equation is one type of nonlinear first-order ODE. It is nonlinear due to the presence of quadratic terms in it, e.g. the $F^{2}$ component in (B.6). In the current case, although function $F$ can be found in closed-form, the solution is fairly complicated and contains complex algebra.

To overcome this difficulty, Selby and Strickland (1995) make a simple substitution

$$
H(s)=\exp \left[-\frac{1}{2} \xi^{2} \int_{t}^{s} F(u) d u\right]
$$

This substitution transforms the nonlinear ODE in (B.6) into an equivalent linear secondorder ODE for $H$. Under this substitution, functions $F$ and $K$ can be rewritten as

$$
\begin{gathered}
F(\tau)=-\frac{2}{\xi^{2}} \frac{H^{\prime}(\tau)}{H(\tau)} \\
K(\tau)=\bar{\lambda}(D(\tau)-\tau)-\frac{2 \gamma \bar{v}}{\xi^{2}} \ln H(\tau) .
\end{gathered}
$$

Therefore the solution to the bond pricing formula in (B.4) amounts to evaluating $H(\tau)$ and $H^{\prime}(\tau)$. A further substitution

$$
\begin{gathered}
\tau=-\frac{1}{\alpha} \ln (x), \quad 0 \leq x \leq 1 \\
H(\tau)=x^{\beta} Q(x)
\end{gathered}
$$

reduces the ODE for $H$ to a homogeneous linear ODE of second order for $Q$, which can be solved by using a standard series solution method. Once we obtain the solution to $Q$, we can retrace, substituting $Q$ back into (B.11) for $H$, and then substituting $H$ back into (B.9) and (B.10) for $F$ and $K$, respectively. For computational details, please refer to Selby and Strickland (1995).

\section{B.1.2 The coupon bond pricing formula with non-zero recovery rate}

Using a no-arbitrage argument, we know that the price of a default-free coupon bond is the sum of the values of individual claims to its remaining coupon payments and its principal, where each of these claims can be regarded as a zero-coupon bond. This is the so-called "portfolio of zeros" approach to valuing a riskless coupon bond. In contrast, when default is a factor, this "portfolio of zeros" approach needs some reconsideration since all 
remaining coupons now share the same default time if default occurs at or before time $T$. However, this approach is theoretically justified in Duffie and Singleton (1999) provided that $\lambda_{j t}$ and $L_{j t}$ are "exogenous," in that they do not depend on the value of the defaultable claim itself, as is the case when pricing corporate bonds. This exogenous assumption is valid in our framework since we are pricing corporate bonds and the recovery rate is assumed to be fixed.

We denote by $G(t, T, c p)$ the price of a default-free coupon bond that pays $c p$ dollars at date $T$ and every six months (i.e. 0.5 years, see equation (B.12)) below) before $T$. In addition, at the maturity date $T$, the bond also pays its holder the principal value of one dollar. Similarly, we use $B_{j}(t, T, c p, 0)$ to denote an otherwise equivalent corporate coupon bond with zero recovery in the event of default. No-arbitrage arguments tell us that we can apply the "portfolio of zeros" approach to value these two coupon bonds as

$$
\begin{aligned}
G(t, T, c p) & =c p \sum_{k=1}^{N} G(t, t+0.5 k, 0)+G(t, T, 0), \\
B_{j}(t, T, c p, 0) & =c p \sum_{k=1}^{N} B_{j}(t, t+0.5 k, 0,0)+B_{j}(t, T, 0,0),
\end{aligned}
$$

where in both equations (B.12) and (B.13), $N$ is the total number of coupon payments and is equal to $2(T-t)$. The riskless zero-coupon bond prices that comprise equation (B.12) are given by a well-known closed-form formula (see, for example, Pearson and Sun (1994)). The zero-coupon corporate bond prices in (B.13), such as $B_{j}(t, T, 0,0)$, are also in analytical form, and can be derived using equation (4) and the Selby and Strickland method.

Finally, we denote by $B_{j}(t, T, c p, 1-L)$ the time $t$ price of a corporate coupon bond with a constant recovery rate of $1-L$. The assumption made on recovery rate in this paper implies that upon default at time $\tau_{d}\left(t<\tau_{d} \leq T\right)$, the bondholder essentially receives a $1-L$ fraction of an otherwise equivalent riskless bond. As a result, beginning at $\tau_{d}$, the bondholder is going to receive $c p(1-L)$ dollars of coupon payment every six months prior to $T$. At time $T$, she is going to receive a total of $(1-L)(1+c p)$ dollars of final coupon payment plus principal. A modification of equation (10) shows that the value of $B_{j}(t, T, c p, 1-L)$ is equal to

$$
B_{j}(t, T, c p, 1-L)=(1-L) G(t, T, c p)+L B_{j}(t, T, c p, 0) .
$$

\section{B.2 The Kalman filter}

\section{B.2.1 A brief summary of the Kalman filter}

Consider an $n \times 1$ vector of variables observed at time $t, y_{t}$, and a $r \times 1$ unobservable state vector, $\xi_{t}$. The state-space representation of the dynamics of $y_{t}$ is given by

$$
\begin{aligned}
\xi_{t+1} & =F \xi_{t}+\epsilon_{t+1}, \\
y_{t} & =H \xi_{t}+\omega_{t},
\end{aligned}
$$


where $F$ and $H$ are $r \times r$ and $n \times r$ matrices, respectively. The $r \times 1$ vector $\epsilon_{t}$ and $n \times 1$ vector $\omega_{t}$ are vectors of white noise, $E\left(\epsilon_{t} \epsilon_{\tau}^{\prime}\right)=Q$ and $E\left(\omega_{t} \omega_{\tau}^{\prime}\right)=R$, for $t \neq \tau$. Here, $Q$ and $R$ are of dimensions $r \times r$ and $n \times n$, respectively. In addition, the disturbances $\epsilon_{t}$ and $\omega_{t}$ are assumed to be uncorrelated at all lags. In the Kalman filter setup, equation (B.15) is called the transition equation (or the state equation), and equation (B.16) is called the measurement equation (or the observation equation).

The Kalman filter is an algorithm for calculating linear least squares forecasts of the state vector on the basis of data observed through date $t, \xi_{t+1 \mid t} \equiv E\left(\xi_{t+1} \mid Y_{t}\right)$, where $Y_{t} \equiv\left(y_{t}^{\prime}, \ldots, y_{1}^{\prime}\right)$ and $E\left(\xi_{t+1} \mid Y_{t}\right)$ denotes the linear projection of $\xi_{t+1}$ on $Y_{t}$. It calculates these forecasts recursively, generating $\xi_{1 \mid \mathbf{0}}, \xi_{2 \mid 1}, \ldots, \xi_{T \mid T-1}$ in succession. Associated with each of these forecasts is a variance-covariance matrix based on the one-step-ahead prediction error

$$
P_{t+1 \mid t} \equiv E\left[\left(\xi_{t+1}-\xi_{t+1 \mid t}\right)\left(\xi_{t+1}-\xi_{t+1 \mid t}\right)^{\prime}\right],
$$

which will be used to evaluate the likelihood function.

The key equations for the Kalman filter are

$$
\begin{gathered}
\xi_{t \mid t}=\xi_{t \mid t-1}+P_{t \mid t-1} H^{\prime}\left(H P_{t \mid t-1} H^{\prime}+R\right)^{-1}\left(y_{t}-H \xi_{t \mid t-1}\right), \\
\xi_{t+1 \mid t}=F \xi_{t \mid t}, \\
P_{t \mid t}=P_{t \mid t-1}-P_{t \mid t-1} H^{\prime}\left(H P_{t \mid t-1} H^{\prime}+R\right)^{-1} H P_{t \mid t-1}, \\
P_{t+1 \mid t}=F P_{t \mid t} F^{\prime}+Q .
\end{gathered}
$$

Among these four equations, equations (B.18) and (B.20) belong to the (one-step-ahead) prediction stage; equations (B.17) and (B.19) are for the updating stage, i.e., using the information available through date $t$ to update the previous (one-step-ahead) estimate of $\xi_{t}$.

For a linear and Gaussian model, the method of maximum likelihood estimation (MLE) can be used to estimate parameters of the model. The sample likelihood is given by

$$
\sum_{t=1}^{T} \ln f\left(y_{t} \mid Y_{t-1}\right)
$$

where we have

$$
\begin{gathered}
f\left(y_{t} \mid Y_{t-1}\right)= \\
(2 \pi)^{-\frac{n}{2}}\left|H P_{t \mid t-1} H^{\prime}+R\right|^{-\frac{1}{2}} \exp \left[-\frac{1}{2}\left(y_{t}-H \xi_{t \mid t-1}\right)^{\prime}\left(H P_{t \mid t-1} H^{\prime}+R\right)^{-1}\left(y_{t}-H \xi_{t \mid t-1}\right)\right] .
\end{gathered}
$$

When the measurement equation is nonlinear

$$
y_{t}=H\left(\xi_{t}\right)+\omega_{t},
$$


where $H(\cdot)$ is a nonlinear function, the extended Kalman filter (EKF) can be used to obtain an approximate filter. In particular, we replace the $H\left(\xi_{t}\right)$ function in (B.23) with its firstorder Taylor's approximation around $\xi_{t}=\xi_{t \mid t-1}$ so that

$$
y_{t}=H\left(\xi_{t \mid t-1}\right)+\left.\frac{\partial H\left(\xi_{t}\right)}{\partial \xi_{t}^{\prime}}\right|_{\xi_{t}=\xi_{t \mid t-1}}\left(\xi_{t}-\xi_{t \mid t-1}\right)+\omega_{t} .
$$

The idea behind the EKF is that to treat equation (B.24), together with (B.15), as if they were the true model. It follows that equations (B.17) through (B.20) will have to be modified accordingly. For details, please refer to Hamilton (1994) and Harvey (1990). Also notice that the parameter estimates obtained from the EKF will be quasi-maximum likelihood estimates (QMLE), rather than MLE as in the linear model case. See also Footnote 7.

\section{B.2.2 Details of the transition equations used in estimation}

For estimation of the default-free interest rate model, the components $a$ and $b$ of the transition equation in (12) are given by

$$
\begin{aligned}
a & =\left[\begin{array}{c}
\mu_{1}\left(1-e^{-\phi_{1} / 12}\right) \\
\mu_{2}\left(1-e^{-\phi_{2} / 12}\right)
\end{array}\right] \\
b & =\left[\begin{array}{cc}
e^{-\phi_{1} / 12} & 0 \\
0 & e^{-\phi_{2} / 12}
\end{array}\right],
\end{aligned}
$$

and $V\left(F_{t-1}\right)$ is a $2 \times 2$ diagonal matrix with elements

$$
V_{i, i}\left(F_{t-1}\right)=\phi_{i}^{-1} \sigma_{i}^{2}\left[f_{i, t-1}\left(e^{-\phi_{i} / 12}-e^{-2 \phi_{i} / 12}\right)+\frac{\mu_{i}}{2}\left(1-e^{-\phi_{i} / 12}\right)^{2}\right], \text { for } i=1,2 .
$$

For estimation of the stochastic volatility model of credit spreads, the components $a_{j}$ and $b_{j}$ of the transition equation in (14) are

$$
\begin{aligned}
& a_{j}=\left[\begin{array}{c}
\bar{\lambda}\left(1-e^{-\tau \alpha / 12}\right) \\
\bar{v}\left(1-e^{-\tau \gamma / 12}\right)
\end{array}\right], \\
& b_{j}=\left[\begin{array}{cc}
e^{-\tau \alpha / 12} & 0 \\
0 & e^{-\tau \gamma / 12}
\end{array}\right],
\end{aligned}
$$

and $\Gamma\left(\Sigma_{j, t-\tau}\right)$ is a $2 \times 2$ matrix with the two diagonal elements given by $\left(\frac{v_{j, t-\tau}-\bar{v}}{2 \alpha-\gamma}\right)\left(e^{-\tau \gamma / 12}-\right.$ $\left.e^{-2 \tau \alpha / 12}\right)+\frac{\bar{v}}{2 \alpha}\left(1-e^{-2 \tau \alpha / 12}\right)$ and $v_{j, t-\tau} \frac{\xi^{2}}{\gamma}\left(e^{-\tau \gamma / 12}-e^{-2 \tau \gamma / 12}\right)+\frac{\xi^{2}}{2 \gamma} \bar{v}\left(1-e^{-\tau \gamma / 12}\right)^{2}$, respectively, and the off-diagonal element is $\rho \xi\left[\frac{\bar{v}}{\alpha+\gamma}\left(1-e^{-\tau(\alpha+\gamma) / 12}\right)+\frac{\left(v_{j, t-\tau}-\bar{v}\right)}{\alpha}\left(e^{-\tau \gamma / 12}-e^{-\tau(\alpha+\gamma) / 12}\right)\right]$, where we recall that $\tau$ indicates the number of months elapsed between successive observations of corporate bond prices of firm $j$. 


\section{B.3 The conditional moments of the stochastic volatility model of credit spreads}

Assume that an $n \times 1$ vector $X_{t}$ follows the stochastic differential equation (SDE)

$$
d X_{t}=U\left(X_{t} ; \Psi\right) d t+\Sigma\left(X_{t} ; \Psi\right) d W_{t},
$$

where $W_{t}$ is an $n \times 1$ vector of independent standard Brownian motions. If $U\left(X_{t} ; \Psi\right)$ and $\Sigma\left(X_{t} ; \Psi\right) \Sigma\left(X_{t} ; \Psi\right)^{\prime}$ are affine functions of $X_{t}$ so that $U\left(X_{t} ; \Psi\right)$ can be written in the form of $G+K X_{t}$, where $G$ and $K$ are matrices of dimension $n \times 1$ and $n \times n$, respectively, then the mean and variance of $X_{t+h}$, conditional on $X_{t}$, are also affine functions of $X_{t}$ as long as $K$ is diagonable (i.e., all of the eigenvalues of $K$ are distinct). Here $h$ denotes a sufficiently small length of time.

Denote the eigenvalue decomposition of $K$ by $Q k Q^{-1}$, where $Q=\left[\begin{array}{llll}Q_{1} & Q_{2} & \ldots & Q_{n}\end{array}\right]$ and $Q_{i}$, $i=1,2, \ldots, n$, are the $n$ linearly independent eigenvectors of $K$, and $k$ is a square diagonal matrix with elements along its main diagonal being the $n$ distinct eigenvalues of $K$. Then Duan and Simonato (1999) show that the conditional mean of $X_{t+h}, E\left(X_{t+h} \mid X_{t}\right)$, is given by

$$
E\left(X_{t+h} \mid X_{t}\right)=Q e^{k h} Q^{-1} X_{t}+Q\left(e^{k h}-I\right) k^{-1} Q^{-1} G,
$$

which is clearly affine in $X_{t}$. Similarly, we can compute the conditional variance of $X_{t+h}$, $\operatorname{Var}\left(X_{t+h} \mid X_{t}\right)$. The required formulas for which can be found in Appendix B in Duan and Simonato (1999).

We can use the above result to derive the conditional moments of the stochastic volatility model of credit spreads. The model is

$$
\begin{aligned}
d \lambda_{j t}^{*} & =\alpha\left(\bar{\lambda}-\lambda_{j t}^{*}\right) d t+\sqrt{v_{j t}} d z_{1 j, t}, \\
d v_{j t} & =\gamma\left(\bar{v}-v_{j t}\right) d t+\xi \sqrt{v_{j t}} d z_{2 j, t},
\end{aligned}
$$

where $\operatorname{corr}\left(z_{1 j, t}, z_{2 j, t}\right)=\rho$. Using a change of variable technique, we can rewrite the above model as

$$
\begin{gathered}
d \lambda_{j t}^{*}=\alpha\left(\bar{\lambda}-\lambda_{j t}^{*}\right) d t+\sigma \eta \sqrt{u_{j t}} d z_{2 j, t}+\sqrt{u_{j t}} d z_{3 j, t}, \\
d u_{j t}=\gamma\left(\bar{u}-u_{j t}\right) d t+\eta \sqrt{u_{j t}} d z_{2 j, t},
\end{gathered}
$$

where $u_{j t} \equiv\left(1-\rho^{2}\right) v_{j t}, \bar{u} \equiv\left(1-\rho^{2}\right) \bar{v}, \eta \equiv \sqrt{1-\rho^{2}} \xi$, and $\sigma \equiv \frac{\rho}{\eta \sqrt{1-\rho^{2}}}$. The two Brownian motions $z_{2 j, t}$ and $z_{3 j, t}$ are now independent. We can rewrite the model in (B.28) in matrix form similar to equation (B.25) as

$$
\begin{gathered}
G=\left[\begin{array}{l}
\alpha \bar{\lambda} \\
\gamma \bar{u}
\end{array}\right], K=\left[\begin{array}{cc}
-\alpha & 0 \\
0 & -\gamma
\end{array}\right], \\
X_{t}=\left[\begin{array}{c}
\lambda_{j t}^{*} \\
u_{j t}
\end{array}\right], d W_{t}=\left[\begin{array}{c}
d z_{2 j, t} \\
d z_{3 j, t}
\end{array}\right],
\end{gathered}
$$


and

$$
\Sigma\left(X_{t} ; \Psi\right)=\left[\begin{array}{cc}
\sigma \eta \sqrt{u_{j t}} & \sqrt{u_{j t}} \\
\eta \sqrt{u_{j t}} & 0
\end{array}\right] .
$$

Notice that in the present model, the matrix $K$ is diagonable if and only if $\alpha \neq \gamma$.

Substituting the above matrices into the formulas in Duan and Simonato (1999), one obtains after some manipulation the conditional moments of this model in terms of the original state variables $\lambda_{j t}^{*}$ and $v_{j t}$ and the model parameters. The conditional means are

$$
\begin{gathered}
E\left(\lambda_{j s}^{*} \mid \lambda_{j t}^{*}\right)=\lambda_{j t}^{*} e^{-\alpha(s-t)}+\bar{\lambda}\left(1-e^{-\alpha(s-t)}\right), \\
E\left(v_{j s} \mid v_{j t}\right)=v_{j t} e^{-\gamma(s-t)}+\bar{v}\left(1-e^{-\gamma(s-t)}\right), \text { for } s \geq t
\end{gathered}
$$

and the conditional variances and covariances are

$$
\begin{gathered}
\operatorname{Var}\left(\lambda_{j s}^{*} \mid \lambda_{j t}^{*}\right)=\left(\frac{v_{j t}-\bar{v}}{2 \alpha-\gamma}\right)\left(e^{-\gamma(s-t)}-e^{-2 \alpha(s-t)}\right) \\
+\frac{\bar{v}}{2 \alpha}\left(1-e^{-2 \alpha(s-t)}\right), \\
\operatorname{Cov}\left(\lambda_{j s}^{*}, v_{j s} \mid \lambda_{j t}^{*}, v_{j t}\right)=\rho \xi\left[\frac{\bar{v}}{\alpha+\gamma}\left(1-e^{-(\alpha+\gamma)(s-t)}\right)+\frac{\left(v_{j t}-\bar{v}\right)}{\alpha}\left(e^{-\gamma(s-t)}\right.\right. \\
\left.\left.-e^{-(\alpha+\gamma)(s-t)}\right)\right], \\
\operatorname{Var}\left(v_{j s} \mid v_{j t}\right)=v_{j t} \frac{\xi^{2}}{\gamma}\left(e^{-\gamma(s-t)}-e^{-2 \gamma(s-t)}\right)+\frac{\xi^{2}}{2 \gamma} \bar{v}\left(1-e^{-\gamma(s-t)}\right)^{2}, \text { for } s \geq t .
\end{gathered}
$$

As $s \rightarrow \infty$, the processes for $\lambda_{j t}^{*}$ and $v_{j t}$ have a steady-state (unconditional) distribution with mean given by $\bar{\lambda}$ and $\bar{v}$, and variance equal to $\frac{\bar{v}}{2 \alpha}$ and $\frac{\xi^{2} \bar{v}}{2 \gamma}$, respectively. In addition, the steady-state covariance between $\lambda_{j s}^{*}$ and $v_{j s}$ is $\bar{v} \frac{\rho \xi}{\alpha+\gamma}$. Finally, the above conditional moments can be derived alternatively using the method of Fisher and Gilles (1996). 


\section{References}

[1] Babbs, S.H. and K.B. Nowman, 1999. Kalman filtering of generalized Vasicek term structure models. Journal of Financial and Quantitative Analysis, 34 (1), 115-130.

[2] Bakshi, G., Madan, D., and F. Zhang, 2001. Investigating the sources of default risk: lessons from empirically evaluating credit risk models. Working Paper, University of Maryland.

[3] Claessens, S. and G. Pennacchi, 1996. Estimating the likelihood of Mexican default from the market prices of Brady bonds. Journal of Financial and Quantitative Analysis, 31 (1), 109-126.

[4] Collin-Dufresne, P., Goldstein, R.S., and J.S. Martin, 2001. The determinants of credit spread changes. Journal of Finance, 56 (6), 2177-2208.

[5] Collin-Dufresne, P. and B. Solnik, 2001. On the term structure of default premia in the swap and LIBOR markets. Journal of Finance, 56 (3), 1095-1115.

[6] Cox, J.C., Ingersoll, J.E. Jr., and S.A. Ross, 1985. A theory of the term structure of interest rates. Econometrica, 53 (2), 385-407.

[7] Dai, Q. and K.J. Singleton, 2000. Specification analysis of affine term structure models. Journal of Finance, 55 (5), 1943-1978.

[8] Das, S.R., 1999. Pricing credit derivatives, in: Francis, J.C., Frost, J.A., and J.G. Whittaker (Eds.), Handbook of Credit Derivatives. McGraw-Hill, 101-138.

[9] David, A., 2002. The dynamic correlation structure between credit spreads and the term-structure of interest rate: the effects of inflation and earnings uncertainty. Working Paper, John M. Olin School of Business, Washington University in St. Louis.

[10] De Jong, F., 2000. Time series and cross-section information in affine term-structure models. Journal of Business \& Economic Statistics, 18 (3), 300-314.

[11] Duan, J.-C. and J.-G. Simonato, 1999. Estimating and testing exponential-affine term structure models by Kalman filter. Review of Quantitative Finance and Accounting, 13, 111-135.

[12] Duffee, G.R., 1998. The relationship between Treasury yields and corporate bond yield spreads. Journal of Finance, 53 (6), 2225-2241.

[13] Duffee, G.R., 1999. Estimating the price of default risk. Review of Financial Studies, $12(1), 197-226$. 
[14] Duffee, G.R. and R.H. Stanton, 2001. Estimation of dynamic term structure models. Working Paper, Haas School of Business, U.C. Berkeley.

[15] Duffie, D. and R. Kan, 1996. A yield-factor model of interest rates. Mathematical Finance, 6 (4), 379-406.

[16] Duffie, D. and D. Lando, 2001. Term structures of credit spreads with incomplete accounting information. Econometrica, 69 (3), 633-664.

[17] Duffie, D. and K.J. Singleton, 1997. An econometric model of the term structure of interest-rate swap yields. Journal of Finance, 52 (4), 1287-1321.

[18] Duffie, D. and K.J. Singleton, 1999. Modeling term structures of defaultable bonds. Review of Financial Studies, 12 (4), 687-720.

[19] Eom, Y.H., Helwege, J., and J.-Z. Huang, 2000. Structural models of corporate bond pricing: an empirical analysis. Working Paper, Yonsei University, Korea. Forthcoming in Review of Financial Studies.

[20] Ericsson, J. and J. Reneby, 2001. The valuation of corporate liabilities: theory and tests. Working Paper, McGill University, Canada.

[21] Fisher, M. and C. Gilles, 1996. Estimating exponential-affine models of the term structure. Working Paper, Federal Reserve Board.

[22] Fong, H.G. and O.A. Vasicek, 1991. Fixed-income volatility management. Journal of Portfolio Management, Summer, 41-46.

[23] Fons, J.S., 1994. Using default rates to model the term structure of credit risk. Financial Analyst's Journal, September/October, 25-32.

[24] Geyer, A.L.J. and S. Pichler, 1999. A state-space approach to estimate and test multifactor Cox-Ingersoll-Ross models of the term structure. Journal of Financial Research, $22(1), 107-130$.

[25] Grinblatt, M., 1995. An analytic solution for interest rate swap spreads. Working Paper, the Anderson School, UCLA.

[26] Hamilton, J.D., 1994. State-space models, in: Engle R.F. and D.L. McFadden (Eds.), Handbook of Econometrics, Volume IV. Elsevier Science B.V., 3039-3080.

[27] Harvey, A.C., 1990. Forecasting, Structural Time Series Models and the Kalman Filter. Cambridge University Press. 
[28] Heston, S.L. and S. Nandi, 2000. A closed-form GARCH option valuation model. Review of Financial Studies, 13 (3), 585-625.

[29] Huang, M. and J.-Z. Huang, 2000. How much of the corporate-Treasury yield spread is due to credit risk?: results from a new calibration approach. Working Paper, Graduate School of Business, Stanford University.

[30] J.P. Morgan, 1999. The J.P. Morgan Guide to Credit Derivatives. Risk Publications.

[31] Lando, D., 1997. Modelling bonds and derivatives with default risk, in: Dempster, M.A.H. and S.R. Pliska (Eds.), Mathematics of Derivative Securities. Cambridge University Press, Cambridge, United Kingdom, 369-393.

[32] Litterman, R. and T. Iben, 1991. Corporate bond valuation and the term structure of credit spreads. Journal of Portfolio Management, Spring, 52-64.

[33] Litterman, R. and J. Scheinkman, 1991. Common factors affecting bond returns. Journal of Fixed Income, June, 54-61.

[34] Liu, J., Longstaff, F.A., and R.E. Mandell, 2000. The market price of credit risk: an empirical analysis of interest rate swap spreads. Working Paper, the Anderson School, UCLA.

[35] Longstaff, F.A. and E.S. Schwartz, 1995. A simple approach to valuing risky fixed and floating rate debt. Journal of Finance, 50 (3), 789-819.

[36] Lund, J., 1997. Econometric analysis of continuous-time arbitrage-free models of the term structure of interest rates. Working Paper, the Aarhus School of Business, Denmark.

[37] Madan, D. and H. Unal, 1994. Pricing the risks of default. Working Paper 94-16-B, Wharton Financial Institutions Center.

[38] Merton, R.C., 1974. On the pricing of corporate debt: the risk structure of interest rates. Journal of Finance, 29 (2), 449-470.

[39] Miu, P., 2001. Performances of alternative reduced form models of credit risk: the role of fitting the default-free term structure. Working Paper, Joseph L. Rotman School of Management, University of Toronto.

[40] Neal, R., Rolph, D., and C. Morris, 2000. Interest rates and credit spread dynamics. Working Paper, Indiana University. 
[41] Nielsen, S.S. and E.I. Ronn, 1997. The valuation of default risk in corporate bonds and interest rate swaps. Advances in Futures and Options Research, 9, 175-196.

[42] Pearson, N.D. and T.-S. Sun, 1994. Exploiting the conditional density in estimating the term structure: an application to the Cox, Ingersoll, and Ross model. Journal of Finance, 49 (4), 1279-1304.

[43] Pedrosa, M. and R. Roll, 1998. Systematic risk in corporate bond credit spreads. Journal of Fixed Income, December, 7-26.

[44] Prigent, J.-L., Renault, O., and O. Scaillet, 2001. An empirical investigation into credit spread indices. Journal of Risk, 3, 27-55.

[45] Selby, M.J.P. and C. Strickland, 1995. Computing the Fong and Vasicek pure discount bond price formula. Journal of Fixed Income, September, 78-84.

[46] Skinner, F.S. and A. Diaz, 2001. On modelling credit risk using arbitrage free models. Working Paper, University of Reading, United Kingdom.

[47] Vasicek, O.A., 1977. An equilibrium characterization of the term structure. Journal of Financial Economics, 5, 177-188.

[48] White, H., 1982. Maximum likelihood estimation of misspecified models. Econometrica, $50(1), 1-25$. 
Table 1

Summary statistics for Moody's credit spread indices

Moody's 10-year and 30-year Aaa and Baa credit spreads (in basis points). The data are monthly for January 1960 - April 2003 (for 10-year spreads) and February 1977 - February 2002 (for 30-year spreads). Source of data: Federal Reserve Board's G.13 release.

\begin{tabular}{lllll} 
& Mean (in bps) & Standard deviation (in \%) & Skewness & Kurtosis \\
\hline \hline 10-year Aaa & 80.44 & 0.50 & 0.72 & 3.37 \\
10-year Baa & 179.73 & 0.70 & 0.37 & 2.71 \\
30-year Aaa & 76.62 & 0.38 & 0.90 & 3.72 \\
30-year Baa & 184.53 & 0.60 & 0.81 & 3.07 \\
\hline
\end{tabular}


Table 2

\section{Summary statistics for Standard \& Poor's credit spread indices}

Standard \& Poor's AAA, AA, A, and BBB credit spreads (in basis points) for various maturities. The data are weekly and cover the sample period August 6, 1996 - September 11, 2001. Source of data: Standard and Poor's.

\begin{tabular}{|c|c|c|c|c|c|c|}
\hline Panel A. AAA & 1 -year & 5 -year & 10-year & 15 -year & 20-year & 25 -year \\
\hline Mean (in bps) & 36.97 & 69.31 & 83.01 & 97.76 & 96.50 & 109.28 \\
\hline Standard deviation (in \%) & 0.24 & 0.28 & 0.32 & 0.40 & 0.35 & 0.38 \\
\hline Skewness & 0.42 & -0.02 & -0.01 & $0.22 \times 10^{-2}$ & 0.07 & 0.04 \\
\hline Kurtosis & 2.28 & 1.55 & 1.57 & 1.56 & 1.67 & 1.66 \\
\hline \multicolumn{7}{|l|}{ Panel B: AA } \\
\hline Mean (in bps) & 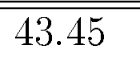 & 84.18 & 101.39 & $\begin{array}{l}118.17 \\
\end{array}$ & 1118.35 & 10132.29 \\
\hline Standard deviation (in \%) & 0.25 & 0.33 & 0.39 & 0.48 & 0.44 & 0.47 \\
\hline Skewness & 0.27 & -0.04 & -0.06 & -0.10 & -0.04 & -0.05 \\
\hline Kurtosis & 1.90 & 1.63 & 1.62 & 1.60 & 1.65 & 1.63 \\
\hline \multicolumn{7}{|l|}{ Panel C: A } \\
\hline 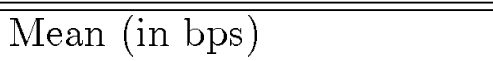 & (67.66 & $\begin{array}{l}111.07 \\
\end{array}$ & 12129.49 & $\begin{array}{l}146.94 \\
\end{array}$ & 10147.59 & $\begin{array}{l}161.91 \\
\end{array}$ \\
\hline Standard deviation (in \%) & 0.36 & 0.44 & 0.49 & 0.58 & 0.53 & 0.56 \\
\hline Skewness & 0.07 & 0.03 & 0.09 & 0.09 & 0.16 & 0.13 \\
\hline Kurtosis & 1.78 & 1.61 & 1.66 & 1.67 & 1.72 & 1.68 \\
\hline \multicolumn{7}{|l|}{ Panel D: BBB } \\
\hline Mean (in bps) & 111.06 & 157.54 & 177.26 & 195.54 & 196.74 & NA \\
\hline Standard deviation (in \%) & 0.58 & 0.62 & 0.65 & 0.73 & 0.68 & NA \\
\hline Skewness & 0.11 & -0.05 & -0.05 & -0.04 & -0.03 & NA \\
\hline Kurtosis & 1.79 & 1.52 & 1.51 & 1.53 & 1.50 & $\mathrm{NA}$ \\
\hline
\end{tabular}


Table 3

\section{Summary statistics for corporate bond data}

Corporate bond data are extracted from the Lehman Brothers Fixed Income Database. Every firm included in the sample must have at least 48 months in which at least 3 qualified bond price observations are available. There are in total 108 such firms over the sample period beginning January 1985 and ending March 1998. In Panel B, yields denote actual yields to maturity on firms' outstanding bonds. In Panel C, credit spreads are defined as the spreads of firms' actual yields to maturity over the riskless interest rates implied by the default-free interest rate model.

\begin{tabular}{lccccc} 
& \multicolumn{5}{c}{ Across 108 firms } \\
\cline { 2 - 6 } Panel A: corporate bonds & Minimum & $1^{\text {st }}$ quartile & Median & $3^{\text {rd }}$ quartile & Maximum \\
\hline \hline Months of data & 48 & 60 & 73 & 88 & 157 \\
Mean number of bonds & 3 & 3.55 & 4.40 & 5.77 & 12.36 \\
Mean years to maturity & 2.46 & 5.42 & 7.92 & 15.12 & 27.79 \\
Minimum years to maturity & 1.02 & 1.02 & 1.06 & 1.59 & 24.19 \\
Maximum years to maturity & 5.03 & 12.02 & 20.25 & 30.39 & 33.44 \\
Mean annual coupon rate & 0 & 7.69 & 8.37 & 9.03 & 11.74 \\
\hline Panel B: yields & & & & & \\
\hline \hline Mean (in bps) & 614.43 & 688.15 & 709.56 & 747.54 & 922.71 \\
Standard deviation (in \%) & 0.52 & 0.65 & 0.77 & 1.04 & 1.99 \\
Skewness & -0.69 & 0.21 & 0.41 & 0.59 & 1.69 \\
Kurtosis & 1.45 & 2.07 & 2.43 & 2.75 & 7.30 \\
\hline Panel C: credit spreads & & & & & \\
\hline \hline Mean (in bps) & 136.85 & 202.45 & 246.07 & 276.57 & 390.20 \\
Standard deviation (in \%) & 0.54 & 0.98 & 1.14 & 1.37 & 2 \\
Skewness & -0.65 & 0.25 & 0.39 & 0.68 & 1.89 \\
Kurtosis & 1.44 & 1.66 & 1.83 & 2.24 & 8.40 \\
\hline
\end{tabular}




\section{Table 4}

\section{Estimation results for the default-free term structure}

The instantaneous default-free interest rate, $i_{t}$, is modeled as

$$
\begin{gathered}
i_{t}=c+f_{1 t}+f_{2 t}, \\
d f_{i t}=\phi_{i}\left(\mu_{i}-f_{i t}\right) d t+\sigma_{i} \sqrt{f_{i t}} d w_{i t}, \quad \text { (under the } P \text { measure) } \\
d f_{i t}=\left(\phi_{i} \mu_{i}-\left(\phi_{i}+\pi_{i}\right) f_{i t}\right) d t+\sigma_{i} \sqrt{f_{i t}} d \widehat{w}_{i t} \text {, (under the } Q \text { measure) }
\end{gathered}
$$

for $i=1,2$. We use an extended Kalman filter approach to estimate the above riskless interest rate model. The data are selected from the CRSP and include month-end price observations of the most recently issued Treasury bonds with maturities closest to 3 and 6 months and 1,2,3,5,10, and 30 years. The robust standard errors for the parameter estimates are calculated following White (1982) and are presented in parentheses.

\begin{tabular}{ccccccc}
$i$ & $\phi_{i}$ & $\mu_{i}$ & $\sigma_{i}$ & $\pi_{i}$ & $\phi_{i}+\pi_{i}$ & $c$ \\
\hline 1 & 0.56 & 0.47 & 0.02 & -0.03 & 0.53 & -0.48 \\
& $(0.0002)$ & $(0.00005)$ & $(0.00006)$ & $(0.00003)$ & & $(0.00028)$ \\
2 & 0.02 & 0.10 & 0.05 & -0.00008 & 0.02 & - \\
& $(0.0005)$ & $(0.00011)$ & $(0.017)$ & $(0.059)$ & & \\
\hline \hline
\end{tabular}

\begin{tabular}{lc}
\hline \hline Bond maturity & RMSE (in bps) \\
\hline 3 months & 30.77 \\
6 months & 17.15 \\
1 year & 4.55 \\
2 year & 10.50 \\
3 years & 8.18 \\
5 years & 4.77 \\
10 years & 10.40 \\
30 years & 18.40 \\
\hline
\end{tabular}


Table 5

Estimation results for the stochastic volatility model of credit spreads

Under the physical measure $P$, firm $j$ ' s instantaneous default probability at time $t, \lambda_{j t}$, is assumed to follow the dynamics

$$
\begin{gathered}
\lambda_{j t}=c_{j}+\lambda_{j t}^{*}+\delta_{1 j}\left(f_{1 t}-\overline{f_{1 t}}\right)+\delta_{2 j}\left(f_{2 t}-\overline{f_{2 t}}\right), \\
d \lambda_{j t}^{*}=\alpha\left(\bar{\lambda}-\lambda_{j t}^{*}\right) d t+\sqrt{v_{j t}} d z_{1 j, t}, \\
d v_{j t}=\gamma\left(\bar{v}-v_{j t}\right) d t+\xi \sqrt{v_{j t}} d z_{2 j, t},
\end{gathered}
$$

where $\operatorname{corr}\left(z_{1 j, t}, z_{2 j, t}\right)=\rho$, and $f_{1 t}$ and $f_{2 t}$ are the two riskless factors of the defaultfree interest rate model. Under the risk-neutral measure $Q$, the processes for $\lambda_{j t}^{*}$ and $v_{j t}$ are

$$
\begin{aligned}
d \lambda_{j t}^{*} & =\left(\alpha \bar{\lambda}-\alpha \lambda_{j t}^{*}+\eta_{1} v_{j t}\right) d t+\sqrt{v_{j t}} d \widehat{z}_{1 j, t}, \\
d v_{j t} & =\left(\gamma \bar{v}-\left(\gamma+\xi \eta_{2}\right) v_{j t}\right) d t+\xi \sqrt{v_{j t}} d \widehat{z}_{2 j, t}
\end{aligned}
$$

where $\operatorname{corr}\left(\widehat{z}_{1 j, t}, \widehat{z}_{2 j, t}\right)=\rho$. An extended Kalman filter approach is adopted to estimate the above stochastic volatility model of credit spreads. The data consist of month-end corporate coupon bond prices, which are assumed to be observed with measurement errors that are normally distributed with mean zero and variance $S_{j}$.

\begin{tabular}{llll} 
Variable & $1^{\text {st }}$ quartile & Median & $3^{\text {rd }}$ quartile \\
\hline \hline$c_{j}$ & -0.437 & -0.061 & -0.054 \\
$\alpha$ & 0.035 & 0.056 & 0.093 \\
$\bar{\lambda}$ & 0.063 & 0.079 & 0.480 \\
$\gamma$ & 0.006 & 0.077 & 0.179 \\
$\bar{v}$ & $0.721 \times 10^{-8}$ & $0.531 \times 10^{-6}$ & $0.886 \times 10^{-6}$ \\
$\xi$ & 0.004 & 0.006 & 0.007 \\
$\rho$ & -0.044 & 0.011 & 0.600 \\
$\delta_{1, j}$ & -0.766 & -0.475 & 0.026 \\
$\delta_{2, j}$ & -0.202 & -0.134 & -0.026 \\
$\sqrt{S_{j}}$ & 0.271 & 0.369 & 0.727 \\
$\eta_{1}$ & 6.379 & 9.956 & 15.770 \\
$\eta_{2}$ & -68.046 & -19.365 & -10.425 \\
$\gamma+\xi \eta_{2}$ & -0.310 & -0.009 & 0.106 \\
Mean fitted $\lambda_{j t}$ & 0.012 & 0.018 & 0.032 \\
Mean fitted $\lambda_{j t}^{*}$ & 0.069 & 0.085 & 0.475 \\
Mean fitted $v_{j t}$ & $0.241 \times 10^{-4}$ & $0.581 \times 10^{-4}$ & $0.121 \times 10^{-3}$ \\
In-sample RMSE (in bps) & 7.27 & 9.30 & 13.11 \\
Out-of-sample RMSE (in bps) & 8.54 & 12.05 & 15.07 \\
\hline
\end{tabular}


Table 6

Estimation results for the benchmark model of credit spreads

In the benchmark model, under the physical measure $P$, firm $j$ 's instantaneous default probability at time $t, \lambda_{j t}$, is given by

$$
\begin{gathered}
\lambda_{j t}=c_{j}+\lambda_{j t}^{*}+\delta_{1 j}\left(f_{1 t}-\overline{f_{1 t}}\right)+\delta_{2 j}\left(f_{2 t}-\overline{f_{2 t}}\right), \\
d \lambda_{j t}^{*}=\kappa_{j}\left(\theta_{j}-\lambda_{j t}^{*}\right) d t+\sigma_{j} \sqrt{\lambda_{j t}^{*}} d u_{j t},
\end{gathered}
$$

where $f_{1 t}$ and $f_{2 t}$ are the two riskless factors of the default-free interest rate model. Under the risk-neutral measure $Q$, the process for $\lambda_{j t}^{*}$ becomes

$$
d \lambda_{j t}^{*}=\left(\kappa_{j} \theta_{j}-\left(\kappa_{j}+\pi_{j}\right) \lambda_{j t}^{*}\right) d t+\sigma_{j} \sqrt{\lambda_{j t}^{*}} d \widehat{u}_{j t} .
$$

We use an extended Kalman filter approach to estimate the benchmark model. The data consist of month-end corporate coupon bond prices, which are assumed to be observed with measurement errors that are normally distributed with mean zero and variance $S_{j}$.

\begin{tabular}{llll} 
Variable & $1^{\text {st }}$ quartile & Median & $3^{\text {rd }}$ quartile \\
\hline \hline$c_{j}$ & 0.006 & 0.011 & 0.015 \\
$\kappa_{j}$ & $0.301 \times 10^{-7}$ & 0.026 & 0.376 \\
$\theta_{j}$ & $0.905 \times 10^{-7}$ & $0.242 \times 10^{-3}$ & 0.002 \\
$\sigma_{j}$ & 0.024 & 0.045 & 0.064 \\
$\delta_{1 j}$ & -0.480 & -0.242 & -0.088 \\
$\delta_{2 j}$ & -0.183 & -0.066 & 0.037 \\
$\sqrt{S_{j}}$ & 0.372 & 0.611 & 1.314 \\
$\pi_{j}$ & -0.567 & -0.326 & -0.191 \\
$\kappa_{j}+\pi_{j}$ & -0.363 & -0.223 & -0.130 \\
Mean fitted $\lambda_{j t}$ & 0.010 & 0.014 & 0.019 \\
Mean fitted $\lambda_{j t}^{*} \sqrt{\lambda_{j t}^{*}}$ & $0.493 \times 10^{-3}$ & 0.003 & 0.006 \\
Mean fitted $\sigma_{j} \sqrt{ }$ & $0.615 \times 10^{-3}$ & 0.002 & 0.005 \\
In-sample RMSE (in bps) & 9.27 & 11.99 & 15.42 \\
Out-of-sample RMSE (in bps) & 11.27 & 13.89 & 17.39 \\
\hline
\end{tabular}


Table $7 \mathrm{~A}$

Estimation results for the stochastic volatility model of credit spreads using Standard \& Poor's credit spread indices

Data used are described in Table 2. Parameters are defined in Table 5.

\begin{tabular}{lllll} 
Variable & AAA & AA & A & BBB \\
\hline \hline$c_{j}$ & -0.059 & -0.073 & -0.159 & -0.060 \\
$\alpha$ & 0.031 & 0.043 & 0.037 & 0.040 \\
$\bar{\lambda}$ & 0.065 & 0.087 & 0.170 & 0.075 \\
$\gamma$ & 0.260 & 0.187 & 0.126 & 0.128 \\
$\bar{v}$ & $0.484 \times 10^{-7}$ & $0.197 \times 10^{-5}$ & $0.373 \times 10^{-5}$ & $0.400 \times 10^{-5}$ \\
$\xi$ & 0.005 & 0.013 & 0.004 & 0.005 \\
$\rho$ & 0.367 & 0.392 & 0.549 & 0.374 \\
$\delta_{1 j}$ & -0.303 & -0.113 & -0.190 & -0.370 \\
$\delta_{2 j}$ & -0.163 & 0.072 & -0.121 & -0.100 \\
$\sqrt{S_{j}}$ & $5.889 \times 10^{-4}$ & $5.515 \times 10^{-4}$ & $6.151 \times 10^{-4}$ & $6.449 \times 10^{-4}$ \\
$\eta_{1}$ & 20.493 & 17.974 & 11.430 & 9.748 \\
$\eta_{2}$ & -35.003 & -0.761 & -30.454 & -18.518 \\
$\gamma+\xi \eta_{2}$ & 0.085 & 0.177 & 0.004 & 0.035 \\
RMSE (in bps) & 5.09 & 4.76 & 5.47 & 5.71 \\
\hline
\end{tabular}


Table 7B

Estimation results for the benchmark model of credit spreads using Standard \& Poor's credit spread indices

Data used are described in Table 2. Parameters are defined in Table 6.

\begin{tabular}{lllll} 
Variable & AAA & AA & A & BBB \\
\hline \hline$c_{j}$ & $-0.297 \times 10^{-3}$ & $-0.476 \times 10^{-3}$ & $-0.185 \times 10^{-3}$ & $0.292 \times 10^{-5}$ \\
$\kappa_{j}$ & 0.170 & 0.157 & 0.080 & 0.019 \\
$\theta_{j}$ & $0.182 \times 10^{-2}$ & $0.226 \times 10^{-2}$ & $0.585 \times 10^{-2}$ & 0.033 \\
$\sigma_{j}$ & 0.070 & 0.072 & 0.065 & 0.064 \\
$\delta_{1 j}$ & -0.085 & -0.062 & -0.080 & -0.164 \\
$\delta_{2 j}$ & 0.110 & 0.153 & 0.200 & 0.287 \\
$\sqrt{S_{j}}$ & $8.784 \times 10^{-4}$ & $9.243 \times 10^{-4}$ & $8.433 \times 10^{-4}$ & $7.916 \times 10^{-4}$ \\
$\pi_{j}$ & -0.266 & -0.263 & -0.158 & -0.070 \\
$\kappa_{j}+\pi_{j}$ & -0.096 & -0.106 & -0.078 & -0.051 \\
RMSE (in bps) & 8.23 & 8.69 & 7.90 & 7.28 \\
\hline
\end{tabular}




\section{Table 8}

Median estimation results for the stochastic volatility model of credit spreads sorted by credit rating

Parameters are defined in Table 5. A firm's credit rating is defined as the mean of the Moody's ratings on the firm's qualified bonds over the sample period used in the estimation of its term structure of credit spreads.

\begin{tabular}{llll} 
Variable & Aa & A & Baa \\
\hline \hline Number of firms & 12 & 60 & 36 \\
$c_{j}$ & $-0.614 \times 10^{-1}$ & $-0.608 \times 10^{-1}$ & $-0.612 \times 10^{-1}$ \\
$\alpha$ & 0.033 & 0.063 & 0.053 \\
$\bar{\lambda}$ & 0.075 & 0.077 & 0.080 \\
$\gamma$ & 0.144 & 0.100 & 0.034 \\
$\bar{v}$ & $0.498 \times 10^{-6}$ & $0.531 \times 10^{-6}$ & $0.510 \times 10^{-6}$ \\
$\xi$ & $0.456 \times 10^{-2}$ & $0.578 \times 10^{-2}$ & $0.558 \times 10^{-2}$ \\
$\rho$ & 0.375 & 0.009 & 0.018 \\
$\delta_{1 j}$ & -0.365 & -0.459 & -0.558 \\
$\delta_{2 j}$ & -0.097 & -0.141 & -0.134 \\
$\eta_{1}$ & 10.059 & 9.385 & 10.870 \\
$\eta_{2}$ & -18.146 & -15.185 & -42.839 \\
$\gamma+\xi \eta_{2}$ & 0.024 & 0.059 & -0.195 \\
Mean fitted $\lambda_{j t}$ & 0.012 & 0.016 & 0.028 \\
Mean fitted $\lambda_{j t}^{*}$ & 0.073 & 0.081 & 0.098 \\
Mean fitted $v_{j t}$ & $0.294 \times 10^{-4}$ & $0.715 \times 10^{-4}$ & $0.637 \times 10^{-4}$ \\
In-sample RMSE (in bps) & 7.66 & 9.41 & 10.69 \\
Out-of-sample RMSE (in bps) & 8.76 & 11.12 & 13.98 \\
\hline
\end{tabular}




\section{Table 9}

Median estimation results for the benchmark model of credit spreads sorted by credit rating

Parameters are defined in Table 6. A firm's credit rating is defined as the mean of the Moody's ratings on the firm's qualified bonds over the sample period used in the estimation of its term structure of credit spreads.

\begin{tabular}{llll} 
Variable & Aa & A & Baa \\
\hline \hline Number of firms & 12 & 60 & 36 \\
$c_{j}$ & 0.006 & 0.009 & 0.014 \\
$\kappa_{j}$ & $0.590 \times 10^{-6}$ & 0.030 & 0.046 \\
$\theta_{j}$ & $0.512 \times 10^{-5}$ & $0.370 \times 10^{-3}$ & $0.508 \times 10^{-3}$ \\
$\sigma_{j}$ & 0.030 & 0.045 & 0.047 \\
$\delta_{1 j}$ & -0.217 & -0.191 & -0.443 \\
$\delta_{2 j}$ & -0.068 & -0.040 & -0.092 \\
$\pi_{j}$ & -0.274 & -0.331 & -0.326 \\
$\kappa_{j}+\pi_{j}$ & -0.274 & -0.226 & -0.208 \\
Mean fitted $\lambda_{j t}$ & 0.007 & 0.013 & 0.021 \\
Mean fitted $\lambda_{j t}^{*}$ & 0.001 & 0.002 & 0.006 \\
Mean fitted $\sigma_{j t} \sqrt{\lambda_{j t}^{*}}$ & $0.152 \times 10^{-2}$ & $0.189 \times 10^{-2}$ & 0.004 \\
In-sample RMSE (in bps) & 9.14 & 12.13 & 13.16 \\
Out-of-sample RMSE (in bps) & 9.82 & 13.08 & 17.35 \\
\hline
\end{tabular}




\section{Table 10A \\ In-sample RMSEs by maturity and credit rating}

Across all 108 firms in the sample, there are in total 38,197 observations on bond prices in the in-sample periods. We report in-sample RMSEs (in bps) for these bonds by maturity and credit rating. The maturity of the bond (M) is measured in years. The credit rating classese are defined according to Moody's ratings on firms' individual bonds.

\begin{tabular}{llll} 
Panel A: maturity & Number of bonds & SV model & Benchmark model \\
\hline \hline $1<\mathrm{M} \leq 5$ & 16,412 & 12.34 & 15.39 \\
$5<\mathrm{M} \leq 10$ & 10,941 & 8.12 & 10.28 \\
$10<\mathrm{M} \leq 15$ & 3,038 & 8.18 & 9.79 \\
$15<\mathrm{M} \leq 20$ & 3,069 & 15.14 & 15.56 \\
$20<\mathrm{M} \leq 25$ & 674 & 13.22 & 13.57 \\
$25<\mathrm{M} \leq 30$ & 3,660 & 14.79 & 15.15 \\
$30<\mathrm{M} \leq 35$ & 403 & 13.03 & 14.22 \\
\hline Panel B: credit rating & & & \\
\hline \hline Aa & 6,023 & 8.30 & 10.77 \\
A & 21,517 & 11.29 & 13.19 \\
Baa & 10,561 & 13.53 & 15.85 \\
Below Baa & 96 & 15.17 & 17.07 \\
\hline
\end{tabular}


Table 10B

Out-of-sample RMSEs by maturity and credit rating

Across all 108 firms in the sample, there are in total 6,101 observations on bond prices in the out-of-sample periods. We report out-of-sample RMSEs (in bps) for these bonds by maturity and credit rating. The maturity of the bond (M) is measured in years. The credit rating classes are defined according to Moody's ratings on firms' individual bonds.

\begin{tabular}{llll} 
Panel A: maturity & Number of bonds & SV model & Benchmark model \\
\hline \hline $1<\mathrm{M} \leq 5$ & 1,858 & 14.38 & 17.39 \\
$5<\mathrm{M} \leq 10$ & 2,035 & 14.82 & 17.41 \\
$10<\mathrm{M} \leq 15$ & 734 & 12.70 & 13.88 \\
$15<\mathrm{M} \leq 20$ & 565 & 15.05 & 16.15 \\
$20<\mathrm{M} \leq 25$ & 119 & 15.93 & 15.02 \\
$25<\mathrm{M} \leq 30$ & 593 & 18.48 & 19.05 \\
$30<\mathrm{M} \leq 35$ & 197 & 15.66 & 16.40 \\
\hline Panel B: credit rating & & & \\
\hline \hline Aa & 937 & 11.81 & 13.03 \\
A & 3,561 & 14.52 & 16.94 \\
Baa & 1,588 & 17.31 & 19.09 \\
Below Baa & 15 & 8.74 & 13.50 \\
\hline
\end{tabular}




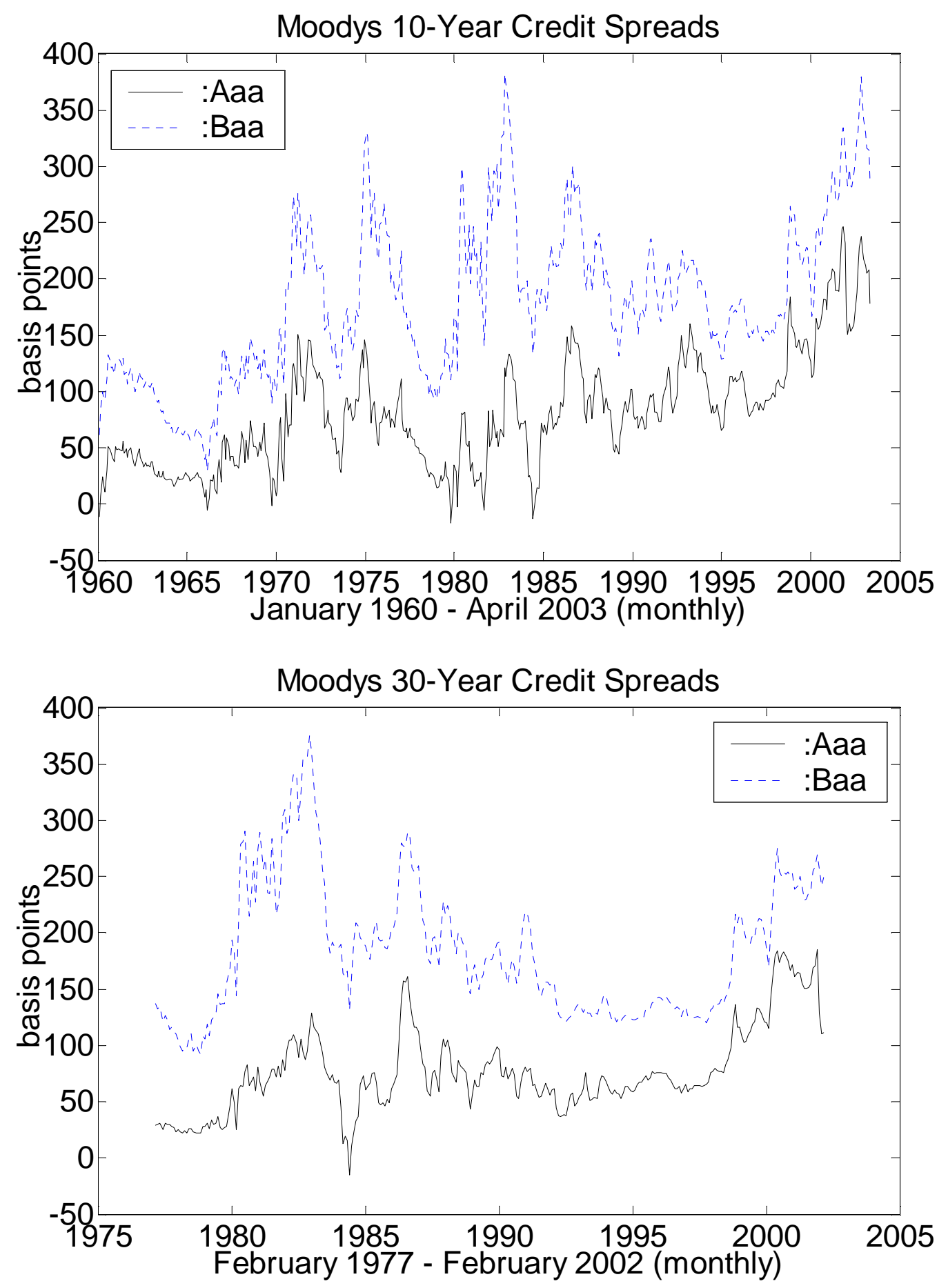

Figure 1: Moody's 10-year and 30-year Aaa and Baa credit spreads (in bps). Data used are described in Table 1. 

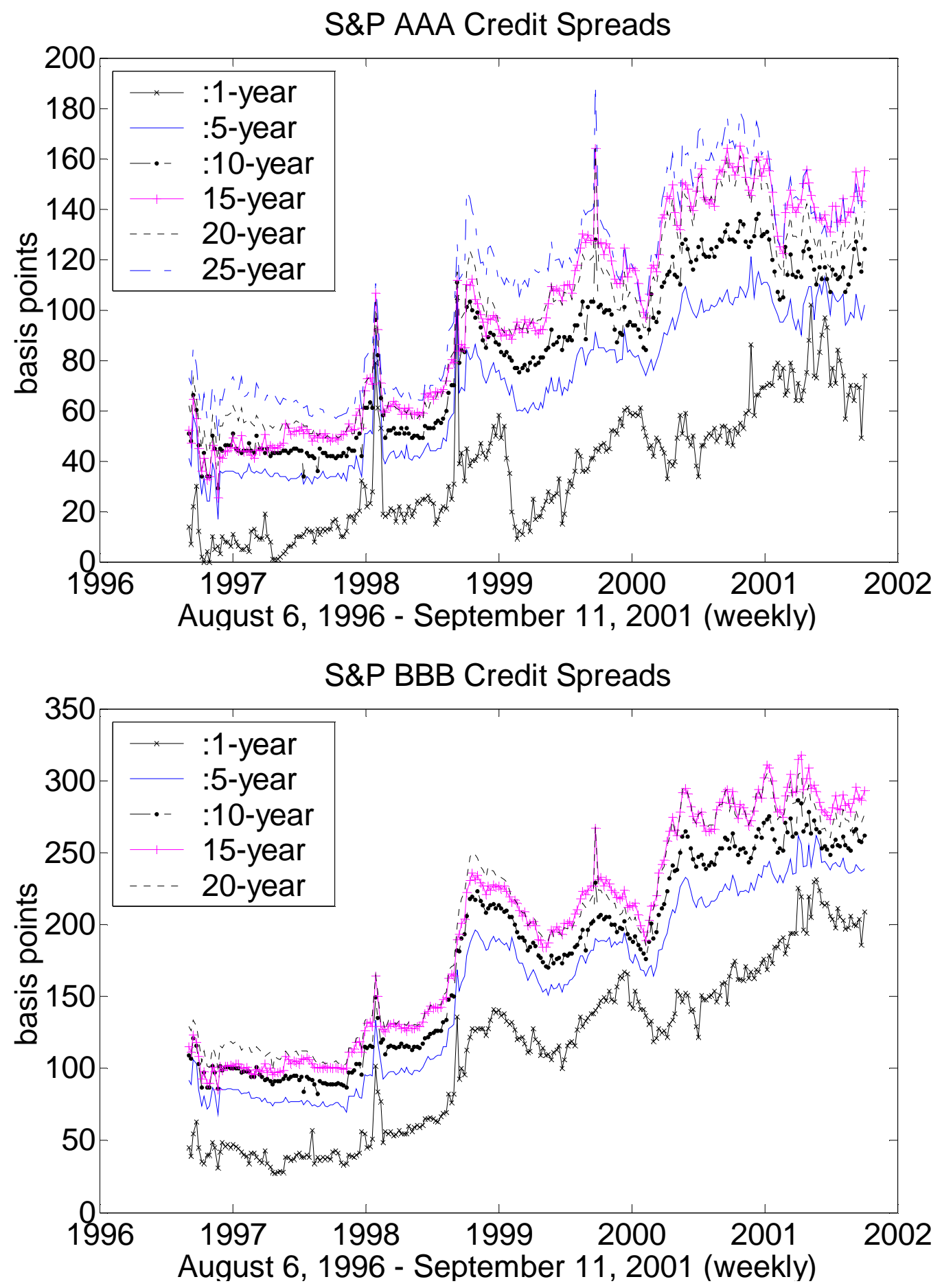

Figure 2: Standard and Poor's AAA and BBB credit spreads (in bps) for various maturities. Data used are described in Table 2. 

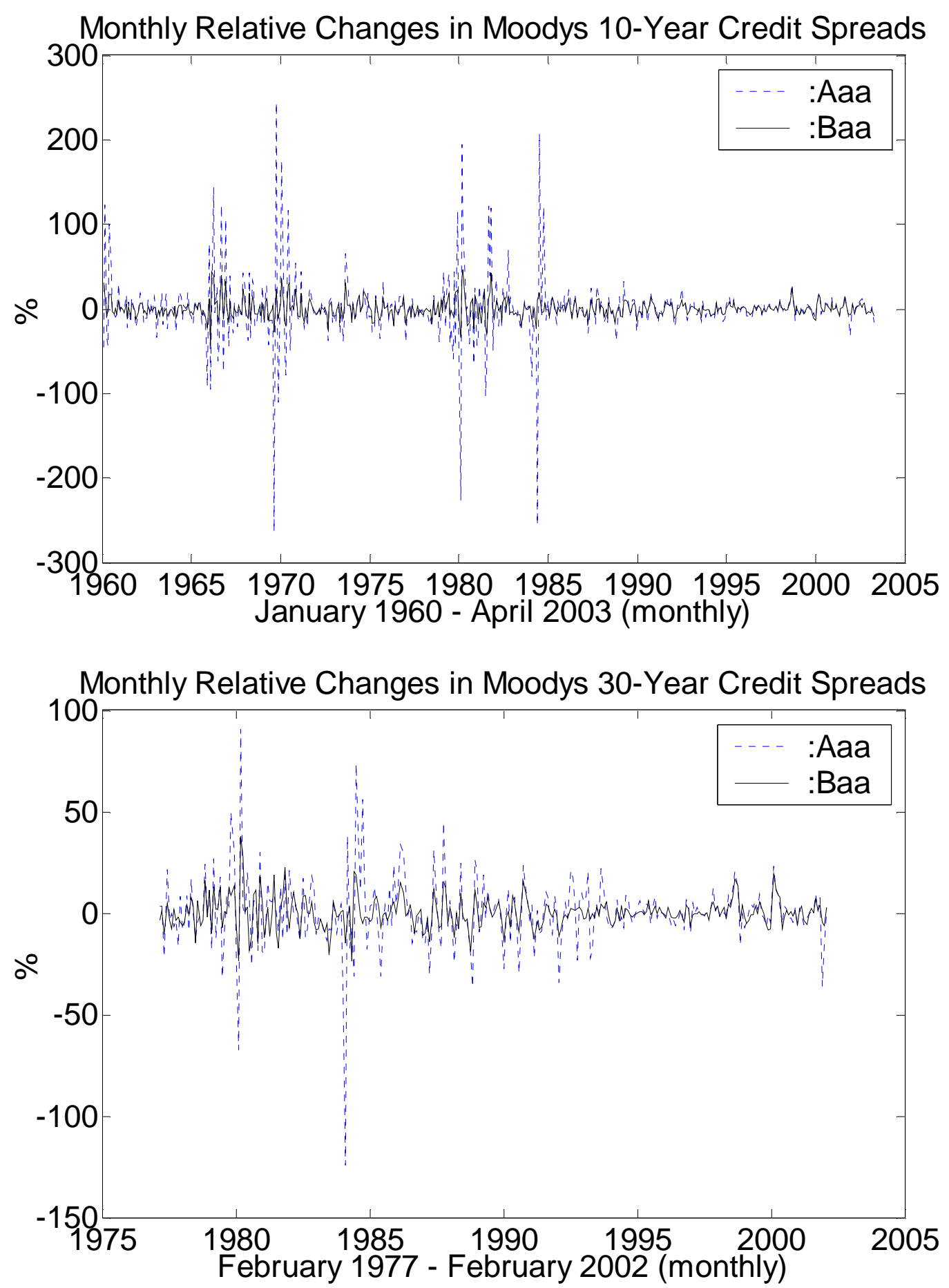

Figure 3: Monthly relative changes in Moody's 10-year and 30-year Aaa and Baa credit spreads. Data used are described in Table 1. Relative change in credit spreads from month $t$ to month $t-1$ is defined as $\ln \left(\mathrm{CS}_{t} / \mathrm{CS}_{\mathrm{t}-1}\right)$, where $\mathbf{C S}_{\mathfrak{t}}$ denotes credit spread in month $\mathbf{t}$. 


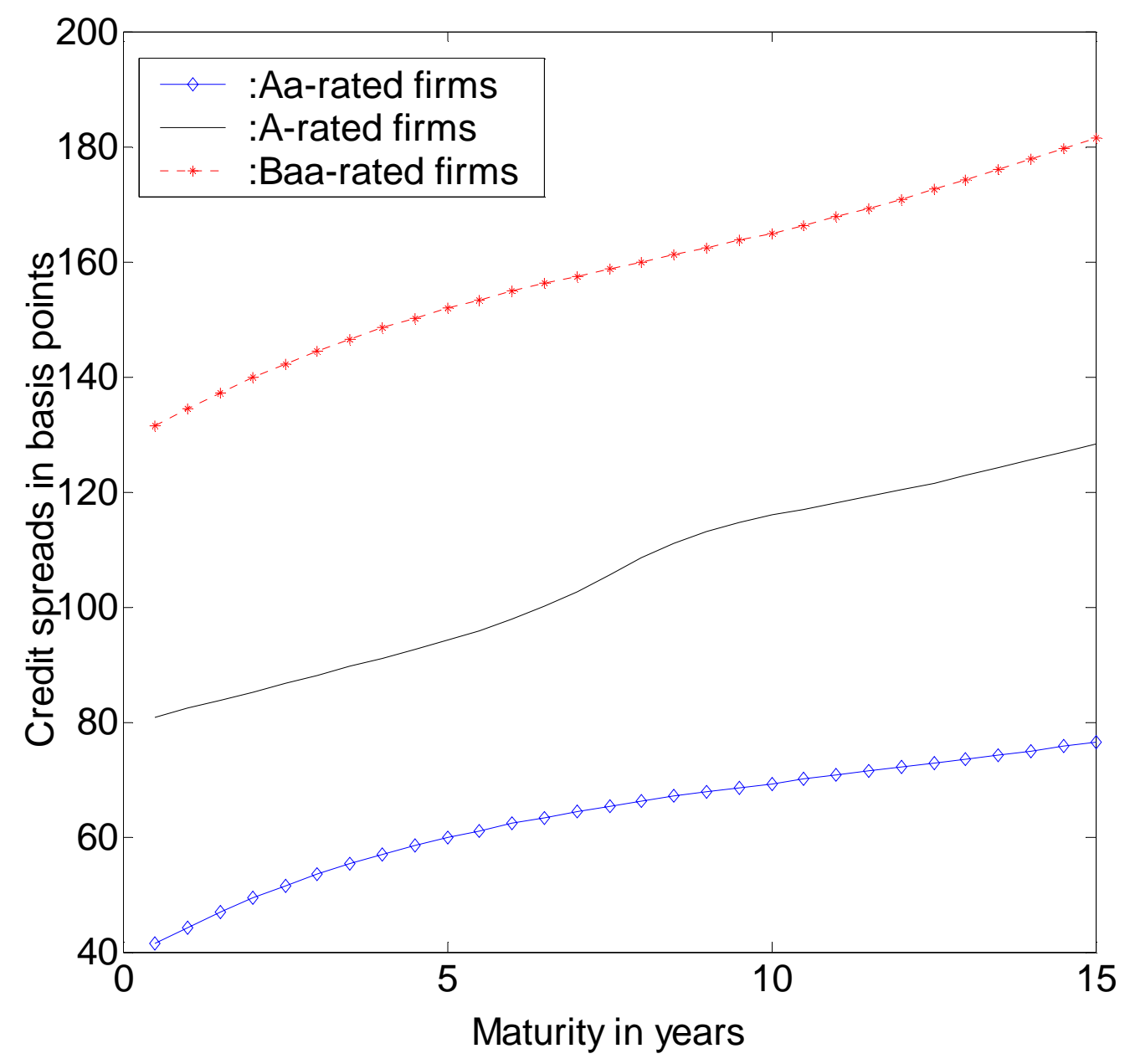

Figure 4: The average credit spreads of the Aa-, A-, and Baa-rated firms implied by the stochastic volatility model of credit spreads. 


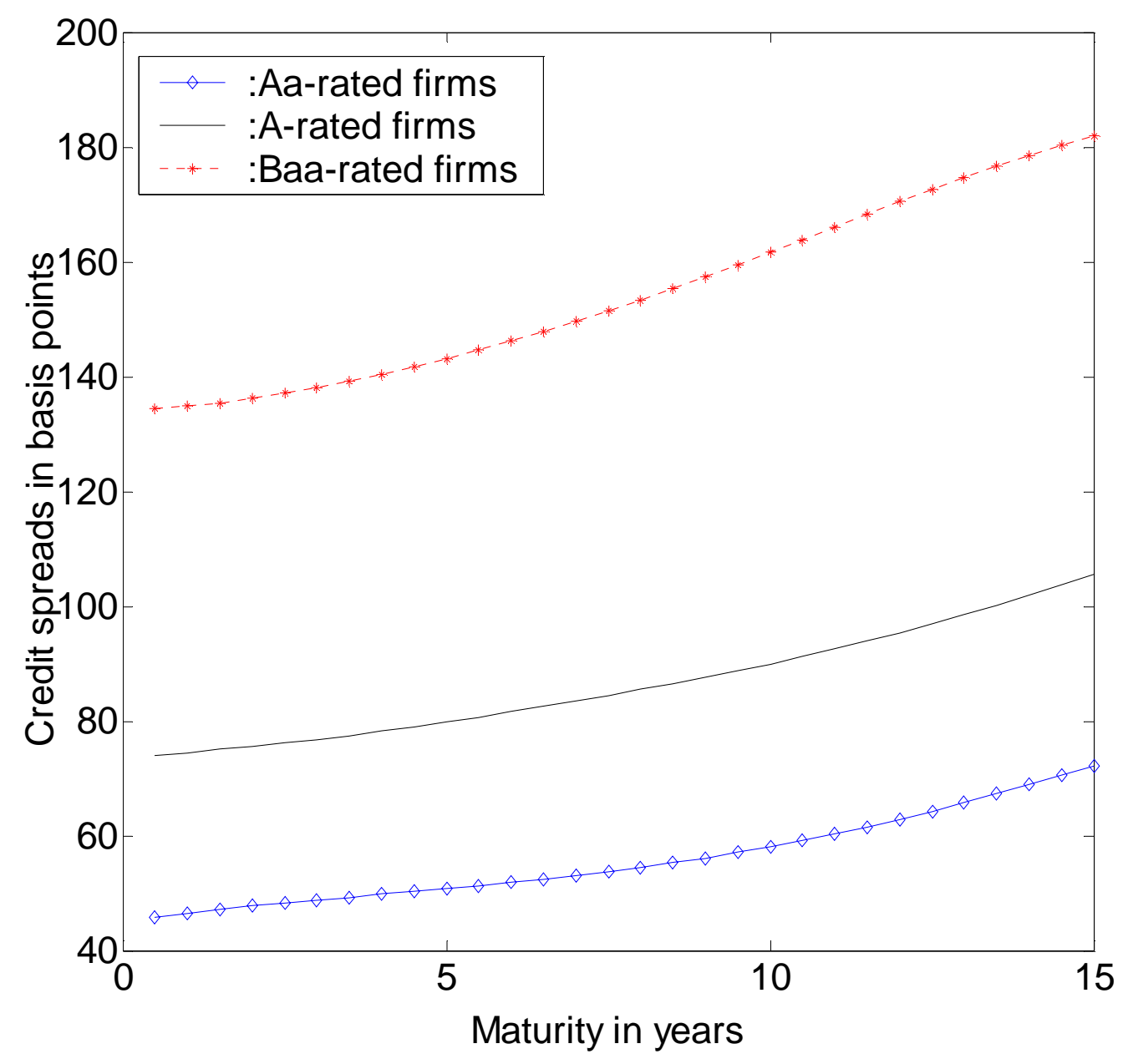

Figure 5: The average credit spreads of the Aa-, A-, and Baa-rated firms implied by the benchmark model of credit spreads. 